\section{Empfehlungen zur Diagnostik, Therapie und Prävention von Pneumonien bei erworbenem Immundefizit}

Deutsche Gesellschaft für Pneumologie

Recommendations for the Diagnosis, Therapy and Prevention of Pneumonia in the Immunocompromised Host

\begin{tabular}{lc}
\hline Inhalt & Seite \\
\hline I. Einleitung & 1 \\
\hline II. Humorale Immundefizienzen & 2 \\
\hline III. Neutropenie & 6 \\
\hline IV. Organtransplantation & 9 \\
\hline V. Immunsuppressive Therapie bei Systemerkrankungen & 12 \\
\hline VI. HIV-Infektion & 13 \\
\hline VII. Gezielte Therapie opportunistischer Erkrankungen & 15 \\
\hline VIII. Prävention respiratorischer Infektionen bei Immundefizit & 18 \\
\hline Literatur & 22 \\
\hline
\end{tabular}

\section{Einleitung}

\section{Epidemiologie}

Pulmonale Infektionen sind häufige Erkrankungen bei immunkompromittierten Patienten, da die tiefen Atemwege eine entscheidende Rolle in der Auseinandersetzung zwischen Umweltnoxen und dem inneren Wirtsmilieu spielen. Alle Faktoren, die mit Beeinträchtigung der systemischen Wirtsabwehr einhergehen, können zur Etablierung pulmonaler Infektionen führen. In der Vergangenheit handelte es sich in der Erwachsenenmedizin um seltene Komplikationen. Angeborene Immundefizienzen standen im Vordergrund. Sie manifestierten sich in der Kindheit und aufgrund limitierter Behandlungsmöglichkeiten erreichte die Mehrzahl der Patienten das Erwachsenenalter nicht. Dies hat sich in den letzten 30 Jahren grundlegend geändert. Die Entwicklung hochwirksamer zytotoxischer Medikamente revolutionierte die Behandlung maligner Tumoren und autoimmuner Erkrankungen. Aufgrund neuer Operationstechniken und immunsuppressiver Verfahren wurde die Transplantation von Knochenmark und einer Reihe solider Organe mit guten Langzeitergebnissen möglich. Mit diesen Fortschritten nahm die Anzahl immunsupprimierter Patienten kumulativ zu. So wurden 1999 in Deutschland 3896 Transplantationen solider Organe $(\bumpeq$ 47/1000 000 Einwohner) vorgenommen [1].

Parallel dazu gelang es, die Betreuung von Patienten mit angeborenen Immundefekten zu verbessern, so dass auch diese zunehmend häufiger das Erwachsenenalter erreichen. Letztlich hat die weltweite Epidemie mit dem humanen Immundefizienzvirus (HIV) und dem damit verbundenen T-Helferzelldefizit zu einer zusätzlichen Häufung von Pneumonien bei schwerer Immuninkompetenz geführt. Die HIV-Pandemie bringt es mit sich, dass sich ein relevanter Anteil von zunächst als ambulant erworben klassifizierten Pneumonien als Infektionen immunkompromittierter Menschen erweist. In Westeuropa leben etwa 520000 HIV-Infizierte [2]. Vor Beginn einer effizienten antiretroviralen Therapie betrug der Anteil von HIV-Infizierten im Stadium AIDS etwa $10 \%$. Er hat sich allerdings seit Einführung der antiretroviralen Kombinationstherapie deutlich reduziert. Die Anzahl von AIDS-Neuerkrankungen erhöhte sich von 1988 bis 1995 von 10000 auf 25000 Fälle jährlich und fiel seitdem auf 15000 Fälle

\section{Institutsangaloen ${ }^{1}$ Universitätsklinikum Lübeck, Med. Klinik III ${ }^{2}$ Augusta Krankenanstalten Bochum ${ }^{3}$ Universitätsklinikum Carl Gustav Carus, Medizinische Klinik und Poliklinik I ${ }^{4}$ Kreiskrankenhaus Lüdenscheid, Abteilung Innere II ${ }^{5}$ Universitätsklinikum Lübeck, Institut für Med. Mikrobiologie und Hygiene ${ }^{6}$ Medizinische Hochschule Hannover, Abteilung für Pneumologie ${ }^{7}$ Universitätsklinikum Essen, Klinik und Poliklinik für Kinder- und Jugendmedizin ${ }^{8}$ Otto-von Guericke Universität Magdeburg, Zentrum für Innere Medizin ${ }^{9}$ Universitätskliniken des Saarlandes, Innere Medizin V}

Korrespondenzadresse Prof. Dr. med. K. Dalhoff · Medizinische Klinik III, Universitätsklinikum Lübeck · Ratzeburger Allee $160 \cdot 23538$ Lübeck·E-mail: klaus.dalhoff@medinf.mu-luebeck.de 
in Westeuropa. Der mit der Therapie verbundene Anstieg der T-Helferzellzahlen ist jedoch grundsätzlich vorübergehend, da sich im Laufe der Therapie Resistenzen bei HI-Viren ausbilden können. Daher ist es fraglich, ob der Rückgang opportunistischer Infektionen in den nächsten Jahren anhält.

\section{Methodische Vorbemerkung}

Aufgrund der stürmischen Entwicklung in der Epidemiologie von Pneumonien bei Immundefizienz ist es verständlich, dass Diagnose- und Therapieansätze zunächst probatorisch eingesetzt wurden. So wurden bei Infektionen im Rahmen von Fieber unter Neutropenie erst nach 1980 systematische Studien durchgeführt. Dies führte ab 1990 zu ersten empirisch begründeten Therapieempfehlungen $[3,4]$. Die Verwendung avancierter diagnostischer Methoden wie der bronchoalveolären Lavage und der thorakalen Computertomographie wurde zumeist ohne empirische Grundlage empfohlen [5,6]. Da die Daten, die klinischen Entscheidungen in der Diagnostik und Therapie zugrunde liegen, inhomogen sind, ist bei der Formulierung von klinischen Empfehlungen zu fordern, dass eine Wertung der Evidenz, die der Empfehlung zugrunde liegt, vorgenommen wird. Die Verbindlichkeit einer Empfehlung sollte von der Solidität der wissenschaftlichen Evidenz abhängig sein. Im Folgenden wird daher eine Rangfolge von Evidenzen verwandt, die auf der Aussagekraft und Validität klinischer Studien und Beobachtungen fußt (Tab.1).

\section{Tab. 1 Evidenzgrade}

Grad I Evidenz aufgrund mindestens einer gut angelegten, prospektiven, randomisierten, kontrollierten Studie

Grad II Evidenz aufgrund mindestens einer nichtrandomisierten, gut angelegten klinischen Studie, vorzugsweise Fall-KontrollStudien und Kohortenstudien, oder aufgrund überzeugender Ergebnisse einer unkontrollierten Beobachtung an einer Patientenserie

Grad III Meinung von Experten des Gebietes auf der Basis klinischer Erfahrung, deskriptiver Beobachtungen oder aufgrund von publizierten Stellungnahmen von Expertenkomitees

Diese Empfehlungen wenden sich an im ambulanten und stationären Bereich tätige Internisten und Pneumologen, die an der Betreuung von Patienten mit Immundefizienzen beteiligt sind. Sie sollen eine rasche Orientierung insbesondere für nichtspezialisierte Kollegen bieten, die die initiale Diagnostik und Therapie von respiratorischen Erkrankungen bei Immundefizit durchführen, Kollegen anderer Fachdisziplinen hinsichtlich der pneumologischen Diagnostik und Therapie bei ihren Patienten beraten oder eine Langzeittherapie bzw. -prophylaxe überwachen. Wegen der Vielfalt der Erkrankungen wurde eine relativ detaillierte Darstellung gewählt, um dem Anwender die Möglichkeit zum Nachlesen einzelner Maßnahmen zu bieten. Die wissenschaftlichen Grundlagen der angegebenen Evidenz wurden durch eine computergestützte Literaturrecherche (Medline) zum Thema erarbeitet. Hierbei wurde die internationale Literatur seit 1980 erfasst. Das Material wurde durch eine Expertengruppe auf einem Arbeitstreffen diskutiert und gewertet. Der im Anschluss hieran entstandene Entwurf zirkulierte mehrfach innerhalb der Arbeitsgruppe. Die Mitglieder der Expertengruppe erhielten keine fi- nanzielle Unterstützung von Dritten. Die Leitlinie wurde dem Vorstand der Deutschen Gesellschaft für Pneumologie zugeleitet und am 11. 9. 2002 nach Überarbeitung angenommen. Zur weiteren Verbreitung der Leitlinie folgt eine Internet-Zusammenfassung, die auf der Webseite der DGP publiziert wird. Eine Aktualisierung dieser Leitlinie ist in 3 Jahren geplant.

\section{Grundlagen der mikrobiologischen Diagnostik}

Eine qualifizierte, in enger Abstimmung zwischen Kliniker und Mikrobiologen durchgeführte infektiologische Diagnostik ist von zentraler Bedeutung für die Versorgung immunkompromittierter Patienten mit pulmonalen Infiltraten. Auch der Kliniker sollte über orientierende Kenntnisse der Vorteile und Nachteile unterschiedlicher Erregernachweisverfahren und der erforderlichen logistischen Voraussetzungen verfügen. Den Empfehlungen ist daher eine Übersicht zur mikrobiologischen Diagnostik vorangestellt (Tab. 2). Hierbei wird unterschieden zwischen Routineanforderungen, die bei jedem immunkompromittierten Patienten mit Verdacht auf Pneumonie erfolgen sollten, und Spezialanforderungen, deren Indikation im Einzelfall zu prüfen ist.

\section{Humorale Immundefizienzen}

Viele erworbene Immundefizienzen gehen mit einer Kombination zellulärer und humoraler Immundefizienz einher. Eine Übersicht der Erkrankungen, die mit einer sekundären humoralen Immunschwäche assoziiert sind, zeigt Tab. 3. Bei vielen dieser Erkrankungen steht eher die Störung der zellulären Abwehrmechanismen im Vordergrund. Im weiteren soll nur auf die Erkrankungen eingegangen werden, bei denen die humorale Defizienz sowohl klinisch als auch hinsichtlich therapeutischer Konsequenzen relevant ist.

\section{Asplenie \\ Charakterisierung des Immundefektes}

Die funktionelle oder durch therapeutisch indizierte Entfernung des Organs bedingte Asplenie stellt die häufigste Form des erworbenen humoralen Immundefektes dar. Bedingt ist dieser hauptsächlich durch Verlust der Clearancefunktion des Organs für Mikroorganismen und von diesen befallenen Zellen. Infektionen bei diesen Patienten werden vor allem durch Pneumokokken verursacht, aber auch Meningokokken, Escherichia coli, Haemophilus influenzae, Staphylococcus aureus und Streptococcus pyogenes werden in erhöhter Inzidenz gefunden.

\section{Klinik und Differenzialdiagnose}

Diese Infektionen können zu jedem Zeitpunkt nach Splenektomie auftreten; die erhöhte Inzidenz von bakteriellen Infektionen betrifft sowohl Kinder als auch Erwachsene. Kinder sind jedoch insgesamt als stärker gefährdet anzusehen [7]. Die höchste Inzidenz von Infektionen nach Splenektomie findet sich in den ersten zwei Lebensjahren. Pneumokokkeninfektionen bei asplenischen Patienten verlaufen im Vergleich zu Gesunden rapider; das als OPSI („overwhelming postsplenectomy infection“) bezeichnete Sepsissyndrom nach Splenektomie weist eine Letalität von $50-70 \%$ auf [8]. 
Tab. 2 Mikrobiologische Diagnostik von Pneumonien bei erworbenem Immundefizit

\begin{tabular}{|c|c|c|c|}
\hline Erreger & diagnostischer Test & Material und Transport & Bemerkungen \\
\hline \multirow[t]{2}{*}{$\begin{array}{l}\text { Chlamydia pneumoniae } \\
\text { Spezialanforderung }\end{array}$} & $\begin{array}{l}\text { PCR } \\
\text { Zellkultur }\end{array}$ & $\begin{array}{l}\text { BAL }>20 \mathrm{ml} \text {, für Kultur Transport in } \\
\text { Spezialmedium: }<24 \mathrm{~h} 4^{\circ} \mathrm{C} \text { oder bei } \\
-70^{\circ} \mathrm{C}\end{array}$ & $\begin{array}{l}\text { Asymptomatische pulmonale Kolonisierung bei HIV möglich. Wenn ver- } \\
\text { fügbar, ist PCR-Diagnostik aus BAL optimal. Zellkultur ist wenig sensitiv, } \\
\text { aber hochspezifisch - nur in Referenzlabors. }\end{array}$ \\
\hline & Serologie & Serum $1 \mathrm{ml}$ & $\begin{array}{l}\text { Serologie wenig hilfreich: kein IgM in ELISA/Mikroimmunfluoreszenz und } \\
\text { kein Titeranstieg bei Reinfektion, oft stark verzögerte lgG-Titeranstiege }\end{array}$ \\
\hline \multirow[t]{3}{*}{$\begin{array}{l}\text { Legionella pneumophila, } \\
\text { L. micdadei und andere } \\
\text { Legionella spp. } \\
\text { Spezialanforderung }\end{array}$} & $\begin{array}{l}\text { Kultur } \\
\text { Mikroskopie } \\
\text { PCR }\end{array}$ & $\begin{array}{l}\text { Sputum }>5 \text { ml, BAL und Aspirate } \\
>10 \text { ml, Pleurapunktat } \\
\text { Transport: }<2 \text { h RT; }<24 \text { h } 4^{\circ} \mathrm{C}\end{array}$ & $\begin{array}{l}\text { Häufig Granulozyten ohne mikroskopischen Bakteriennachweis im Spu- } \\
\text { tum/BAL. Granulozytose im Sputum ist nicht immer ausgeprägt, daher } \\
\text { Sputum auch bei geringer Granulozytenzahl kulturell untersuchen. Kultur } \\
\text { ist mäßig sensitiv, PCR ist für klinische Materialien nicht kommerziell ver- } \\
\text { fügbar. }\end{array}$ \\
\hline & Blutkultur & $\begin{array}{l}\text { Blut > } 15 \mathrm{ml} \\
\text { Blutkulturmedium }\end{array}$ & $\begin{array}{l}\text { Anzucht ist diagnostisch definitiv - Rücksprache mit dem Labor wegen } \\
\text { der Notwendigkeit blinder Subkulturen aus dem Blutkulturmedium erfor- } \\
\text { derlich. }\end{array}$ \\
\hline & $\begin{array}{l}\text { Legionella-AG } \\
\text { ELISA/RIA }\end{array}$ & $\begin{array}{l}\text { Urin } 1 \mathrm{ml} \\
\text { Transport: <24 h RT }\end{array}$ & $\begin{array}{l}\text { Sensitiv und spezifisch; erfasst nur Legionella pneumophila der Serogrup- } \\
\text { pe } 1 \text { ( } 60-90 \% \text { der Isolate). Antigen bleibt oft Monate positiv, nicht zur } \\
\text { Therapiekontrolle nutzbar. }\end{array}$ \\
\hline
\end{tabular}

Mykobakterien Kultur $\quad 3-6 \times$ Morgensputum, BAL und (M. tuberculosis, NTM) Mikroskopie Aspirate $>10 \mathrm{ml}$, Lungengewebe Routineanforderung $\quad>0,5 \mathrm{~g}$. Transport im wachsfreien (Kultur, Mikroskopie) PCR für TB-Komplex Behälter ohne Zusätze:

Spezialanforderung $(P C R)$

Blutkultur $\quad$ EDTA-Blut $7 \mathrm{ml}$ oder Citrat-Blut 7 ml. Transport: < 1d RT

\begin{tabular}{|c|c|c|}
\hline & Blutkultur & $\begin{array}{l}\text { EDTA-Blut } 7 \mathrm{ml} \text { oder Citrat-Blut } \\
7 \mathrm{ml} \text {. Transport: < 1d RT }\end{array}$ \\
\hline Mycoplasma pneumoniae & Kultur & $\begin{array}{l}\mathrm{BAL}>10 \mathrm{ml} \\
\text { Transport: }<24 \mathrm{~h} 4{ }^{\circ} \mathrm{C}\end{array}$ \\
\hline & Serologie & Serum $1 \mathrm{ml}$ \\
\hline $\begin{array}{l}\text { Nocardia asteroides, } N \text {. } \\
\text { spp., aerobe Aktinomyzeten } \\
\text { Spezialanforderung }\end{array}$ & $\begin{array}{l}\text { Kultur } \\
\text { Mikroskopie }\end{array}$ & $\begin{array}{l}\text { BAL, Aspirate > } 10 \text { ml, Sputum } \\
>5 \text { ml. Transport: }<2 \text { h RT; <24 h } \\
4^{\circ} \mathrm{C} \text { (einige Nocardia spp. kälte- } \\
\text { empfindlich!) }\end{array}$ \\
\hline
\end{tabular}

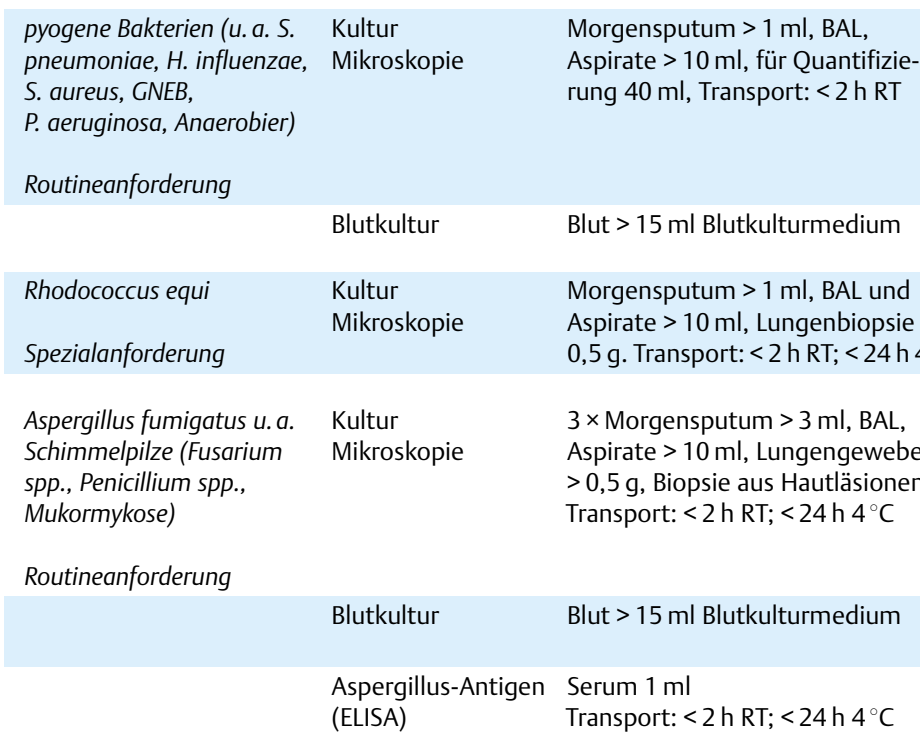

Schneller Transport, um Überwuchern durch Rachenflora zu verrmeiden. Kontamination durch Leitungswasser (nichttuberkulöse Mykobakterien [NTM]) vermeiden. PCR aus Originalmaterial bedarf weiterer Standardisierung. Negative Befunde sind wegen mäßiger Sensitivität kulturell zu bestätigen, positive Befunde nicht beweisend für eine aktive Tuberkulose. In die Bewertung müssen Klinik und Kulturresultat einbezogen werden. Hilfreich zur raschen Differenzierung TB/NTM.

Positive Blutkultur als Zeichen der systemischen Dissemination, häufig bei $<100$ CD4+Zellen/ $\mu$ l.

Kultur langwierig und wenig sensitiv, Überwuchern möglich. PCR ist vorzuziehen, aber nicht kommerziell verfügbar.

Serologie (ELISA/KBR) zeigt i. d. R. rasche Titeranstiege. AK können > 1 Jahr persistieren.

Überwuchern durch Rachenflora in Sputum möglich. Bakteriämie ist selten. $90 \%$ der Lungenmanifestationen sind durch N.-asteroides-Komplex verursacht. Verlängerte Bebrütungszeiten erforderlich. Speziesdifferenzierung im Speziallabor. Schwerste generalisierte Verläufe bei < 200 CD4+ Zellen $/ \mu$ l.

Granulozyten und Überwiegen einer Bakterienpopulation im SputumGrampräparat sprechen für Pneumonie durch pyogene Bakterien. Quantifizierung aus BAL sinnvoll: Monokultur mit Keimzahl $\geq 10^{4}$ ist i.d.R. klinisch signifikant, bei antibiotischer Vortherapie auch geringere Keimzahlen. Niedrige Sensitivität der Kultur für Anaerobiernachweis bei Aspiration.

Blutkulturentnahme vor Antibiose obligatorisch.

Überwuchern durch Rachenflora in Sputum möglich. Intrazelluläre grampositive Bakterien im Gram-Präparat.

Kolonisation von Infektion schwer abzugrenzen, hoher prädiktiver Wert in Hochrisikosituation (z. B. Neutropenie)

Definitive Diagnose durch mikroskopischen Nachweis der Invasivität in der Lungenbiopsie.

Blutkulturen sind für Schimmelpilze mit Ausnahme von Fusarium spp. nicht hinreichend sensitiv.

Nur für Aspergillus spp. Diagnostisches Potenzial viel versprechend, aber nicht völlig abgeklärt. Wert liegt im Verlauf, nicht in Einzelseren. Bei v. a. invasive Aspergillose Kontrolle $1-3 \times /$ Woche. Positive Resultate nachtesten und kulturell/radiologisch bestätigen. Falsch pos. Resultate sind möglich bei Kontamination mit Sporen aus Staub 


\begin{tabular}{|c|c|c|}
\hline Erreger & diagnostischer Test & Material und Transport \\
\hline $\begin{array}{l}\text { Candida albicans und } \\
\text { andere Hefen (Candida } \\
\text { spp., Trichosporon spp. } \\
\text { u. a.) }\end{array}$ & $\begin{array}{l}\text { Kultur } \\
\text { Mikroskopie } \\
\text { Blutkultur }\end{array}$ & $\begin{array}{l}\text { Sputum }>1 \mathrm{ml}, \mathrm{BAL}>10 \mathrm{ml} \text {, für } \\
\text { Quantifizierung } 40 \mathrm{ml} \text {. Lungen- } \\
\text { gewebe }>0,5 \mathrm{~g} \\
\text { Transport: }<2 \mathrm{~h} \mathrm{RT} ;<24 \mathrm{~h} 4{ }^{\circ} \mathrm{C} \\
\text { Blut }>15 \mathrm{ml} \text { Blutkulturmedium }\end{array}$ \\
\hline Routıneanforderung & $\begin{array}{l}\text { Candida AG/AK- } \\
\text { Nachweis }\end{array}$ & Serum $1 \mathrm{ml}<24 \mathrm{~h}$ RT \\
\hline
\end{tabular}

\begin{tabular}{|c|c|c|}
\hline \multirow{2}{*}{$\begin{array}{l}\text { Cryptococcus neoformans } \\
\text { Spezialanforderung }\end{array}$} & $\begin{array}{l}\text { Kultur } \\
\text { Mikroskopie }\end{array}$ & $\begin{array}{l}\text { BAL }>10 \mathrm{ml} \text {, nativer Liquor }>5 \mathrm{ml} \text {, } \\
\text { Urin }>100 \mathrm{ml}\end{array}$ \\
\hline & & Transport: $<2$ h RT; $<24 \mathrm{~h} 4^{\circ} \mathrm{C}$ \\
\hline & Blutkultur & Blut $>15 \mathrm{ml}$ Blutkulturmedium \\
\hline & Antigen-Nachweis & $\begin{array}{l}\text { Serum } 1 \mathrm{ml} \text {, nativer Liquor } 1 \mathrm{ml} \\
\text { Transport: <24 h RT }\end{array}$ \\
\hline
\end{tabular}

Pneumocystis carinii

Spezialanforderung

Immunfluoreszenz MethenaminSilberfärbung $\mathrm{n}$. Grocott / Gomori (Zysten) Giemsa (orient. Schnellfärbung)

Cryptosporidium parvum

Spezialanforderung

Toxoplasma gondii

Spezialanforderung Aspirate $>10 \mathrm{ml}$. Transport ohne Zusätze: $<2 \mathrm{~h} \mathrm{RT} ;<24 \mathrm{~h} 4^{\circ} \mathrm{C}$ Lungengewebe $>0,5 \mathrm{~g}$, in sterile feuchte Gaze schlagen - nicht in Flüssigkeit: < 15 min RT, $<4 \mathrm{~h} 4^{\circ} \mathrm{C}$

Bemerkungen

Kolonisation ist von Invasion diagnostisch kaum abzugrenzen, Quantifizierung in BAL nur begrenzt hilfreich. Definitive Diagnose nur durch bioptischen Nachweis der Invasion im Lungengewebe. Speziesdifferenzierung ist wegen unterschiedlicher Resistenzprofile relevant (z. B. Fluconazolresistenz von C. krusei).

Die Sensitivität des AG-Nachweises ist bei pulmonaler Infektion gering und auch bei systemischer Infektion mäßig. Der Stellenwert des AKNachweises ist unklar. Die Serologie kann im Individualfall als Verlaufsparameter sinnvoll sein.

Bei positivem pulmonalen Nachweis ist Lumbalpunktion wegen möglicher asymptomatischer ZNS-Invasion empfehlenswert.

Sensitiv bei disseminierter Infektion, falsch-neg. Resultate sind bei singulärer pulmonaler Läsion möglich. Falsch pos. Befunde bei Trichosporonosis möglich. Schlechte Prognose bei initialem Liquor-Titer > 1024. Bei AIDSPatienten meist lebenslang persistierend.

Induziertes Sputum nur bei symptomatischen HIV-Patienten in erfahrenen Labors, andere Materialien bei jeder Immunsuppression. Positives Resultat beweisend - jedoch ist Kreuzreaktivität mit Pilzstrukturen in der Immunfluoreszenz möglich. Positiver Befund oft noch unter Therapie.

mikroskopischer Direktnachweis

Sputum > $1 \mathrm{ml}$, BAL und Aspirate $>10 \mathrm{ml}$

Transport: $<2$ h RT; $<24 \mathrm{~h} 4{ }^{\circ} \mathrm{C}$

Giemsa
PCR, Zellkultur

$\mathrm{BAL}>10 \mathrm{ml}$, Lungengewebe $>0,5 \mathrm{~g}$ Transport: $<2 \mathrm{~h} \mathrm{RT} ;<24 \mathrm{~h} 4^{\circ} \mathrm{C}$

Antigendirektnach- BAL, Aspirate $>10 \mathrm{ml}$, Lungengeweis Zellkultur, PCR webe $>0,5 \mathrm{~g}$, Transport: $<24 \mathrm{~h} 4{ }^{\circ} \mathrm{C}$ Kultur: Virustransportmedium Serum $1 \mathrm{ml}$

BAL, Aspirate $>10 \mathrm{ml}$, Lungengewebe $>0,5 \mathrm{~g}$, Transport: $<24 \mathrm{~h} 4^{\circ} \mathrm{C}$ Kultur: Virustransportmedium Serum $1 \mathrm{ml}$
Intra- und extrazelluläre Tachyzoiten in der Giemsa-Färbung beweisend Auftreten bei $<50$ CD4+Zellen/ $/$ l gehäuft. PCR und Kultur in Referenzzentren.

Material in der Frühphase abnehmen. Bei HIV häufig Ausscheidung in Urin und Faeces, Signifikanz unklar. PCR für alle Subtypen als experimentelle Methode in Speziallabors. 4 facher Titeranstieg in 2-4 Wochen ist diagnostisch, kann aber ausbleiben.

Verlängerte Ausscheidung bei Immunsuppression, Kolonisierung nicht auszuschließen.

PCR als experimentelle Methode in Speziallabors.

4facher Titeranstieg in 2-4 Wochen ist diagnostisch, kann aber ausbleiben.

\section{Diagnostik}

Bei pulmonalen Infektionen sollte zum Erregernachweis neben Blutkulturen auch Sputum gewonnen werden (Grad II) [8]. Wegen des häufig fulminanten Verlaufs sollten die Patienten initial hospitalisiert werden (Grad III). Invasive diagnostische Maßnahmen sind selten erforderlich; prognostisch entscheidend ist die unverzügliche Einleitung einer kalkulierten Therapie. Einen Hinweis auf eine funktionelle Asplenie/Hyposplenie liefert der Befund von Howell-Jolly-Körperchen (Kernreste in unreifen Erythrozyten) im peripheren Blutausstrich.

\section{Therapie}

Die empirische antibiotische Therapie richtet sich gegen das angegebene Erregerspektrum, wobei Infektionen mit Pneumokokken bei weitem überwiegen. Bei ambulant erworbenen Pneumonien sollten parenterale Antibiotika mit hoher Aktivität im grampositiven Bereich ausgewählt werden, die auch gegenüber Neis- serien und H. influenzae wirksam sind. Hierzu gehören Cephalosporine der dritten Generation wie Ceftriaxon und Cefotaxim; bei Verdacht auf die in Deutschland bislang seltenen Penicillinresistenten Pneumokokken wird bis zum Vorliegen des Resistenzprofils zusätzlich ein neueres Fluorchinolon oder Vancomycin empfohlen (Grad III) [8,9]. In diesen Fällen ist immer eine MHK-Testung des Isolats vorzunehmen. Nach internationalem Standard der NCCLS gilt bei Penicillin G eine MHK $\geq 2 \mathrm{mg} / \mathrm{l}$ als resistent. Wir schließen uns jedoch dem aktuellen Statement einer interdisziplinären CDC-Arbeitsgruppe an, die empfiehlt, die Therapie erst ab einer MHK von $\geq 4 \mathrm{mg} / \mathrm{l}$ zu modifizieren, um den Einsatz von Reserveantibiotika und damit die Entwicklung weiterer Resistenzen zu limitieren [9].

\section{Hämatologische Erkrankungen/immunsuppressive Therapie} Bei temporären Störungen, wie unter zytostatischer Therapie, stehen die Störungen der unspezifischen und zellulären Abwehr- 


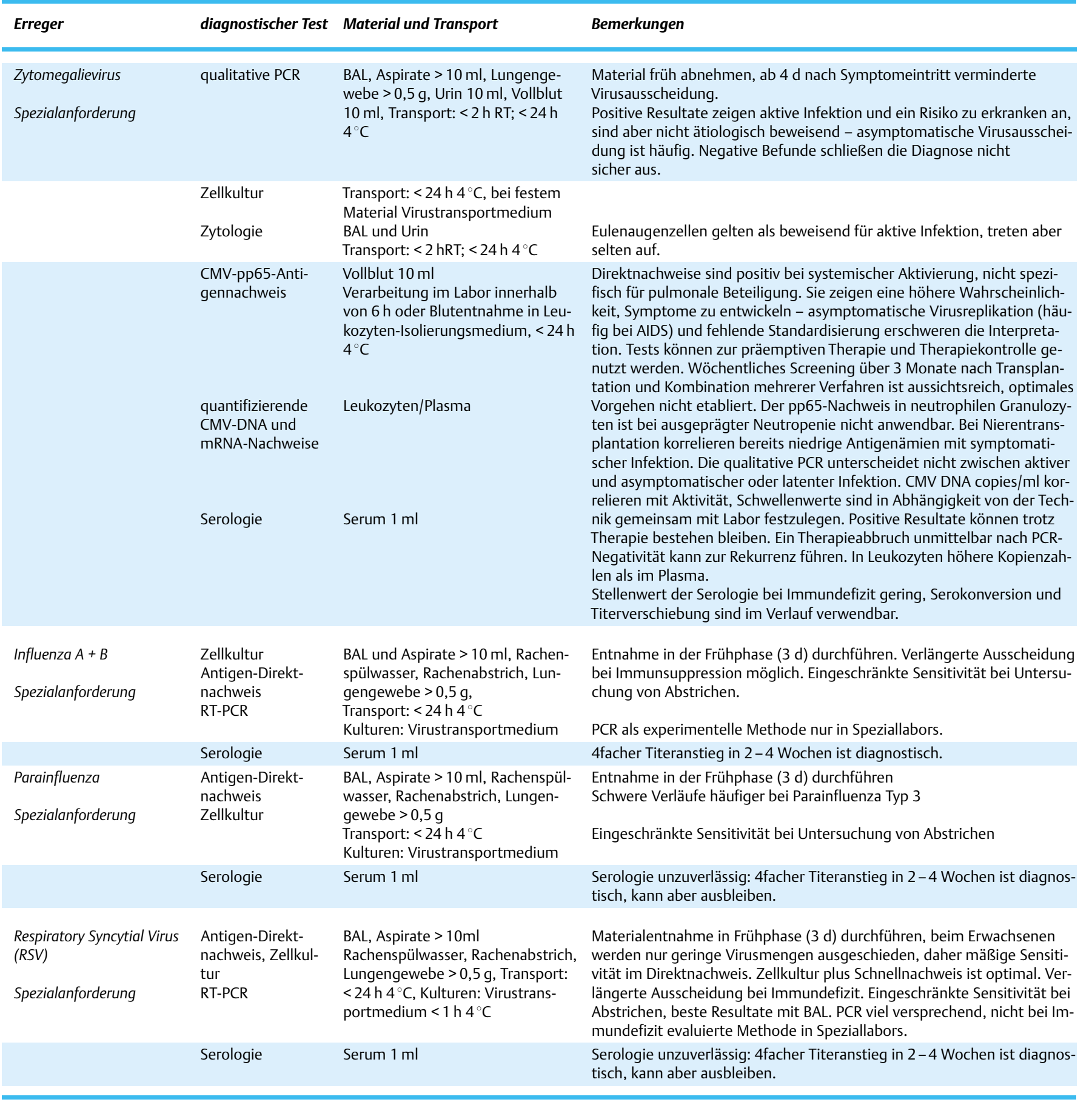

$\mathrm{RT}=$ Raumtemperatur

mechanismen im Vordergrund, da die Latenz bis zum Auftreten humoraler Defizite länger ist. Eine humorale Immundefizienz ist nur bei länger andauernden Phasen der Aplasie wie nach Knochenmarkstransplantation sowie bei chronisch lymphatischen Leukämien und Plasmozytom zu erwarten. Das Erregerspektrum hängt von dem im Vordergrund stehenden Immundefekt (zellulär/humoral), der auch durch therapeutische Maßnahmen beeinflusst wird, ab. Bei vorherrschendem humoralem Immundefizit gelten für Diagnostik und empirische Antibiotikatherapie die gleichen Grundsätze wie bei Asplenie (Grad III).
Darüber hinaus haben bei erwachsenen Patienten mit chronisch lymphatischer Leukämie und sekundärer Hypogammaglobulinämie fünf kontrollierte randomisierte Studien, von denen drei plazebo-kontrolliert durchgeführt wurden, einen positiven Einfluss einer regelmäßigen Immunglobulintherapie auf die Rate systemischer und pulmonaler Infektionen gezeigt (Grad I) [10-13]. Eine eindeutige Kosten-Nutzen-Analyse dieser Therapie ist derzeit nicht möglich, zumal bisherige Studien keinen eindeutigen Effekt auf die Mortalität nachweisen konnten. Bei Patienten mit Plasmozytom wurde eine kontrollierte Cross-overStudie durchgeführt, in der eine Reduktion von Bronchitis und 
Tab. 3 Erkrankungen mit erworbener humoraler Immundefizienz

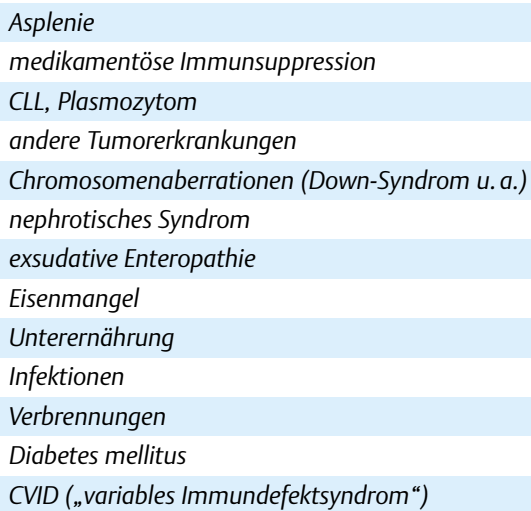

Pneumonien unter Immunglobulingabe nachgewiesen wurde [14]. Diese Befunde müssen in größeren Untersuchungen bestätigt werden, bevor eine eindeutige Empfehlung ausgesprochen werden kann. Für andere Grundkrankheiten sowie für die Anwendung einer Immunglobulintherapie unter immunsuppressiver Therapie und bei pädiatrischen Tumorerkrankungen liegen keine Daten aus kontrollierten Studien vor $[15,16]$.

\section{Neutropenie}

\section{Charakterisierung des Immundefekts}

Ein Immundefekt, der vorwiegend die Neutrophilen betrifft, führt zu einem hohen Infektionsrisiko für Erreger, die überwiegend über phagozytierende Zellen unter Kontrolle gehalten werden, also Bakterien und Pilze. Von einer Neutropenie sprechen wir bei Neutrophilenzahlen $<1,0 \times 10^{9} / \mathrm{ml}$. Von diesem Niveau ab steigt das Risiko für Infektionen mit sinkenden Neutrophilenzahlen. Weitere Faktoren, die das Infektionsrisiko erhöhen, sind die Geschwindigkeit des Neutrophilenabfalls sowie die Dauer der Neutropenie. Hieraus erklären sich wichtige Unterschiede im Risikoprofil von Neutropenien bei soliden und hämatologischen Neoplasien. Im Rahmen der Chemotherapie von soliden Tumoren entstehen Neutropenien relativ langsam, erreichen oft nicht $<0,1 \times 10^{9} / \mathrm{ml}$ und dauern meist nur kurz an (ca. 3-10 Tage). Entsprechend dominieren im Rahmen von Pneumonien bakterielle Erreger. In einer neueren Studie bei Patienten mit bakteriämischen Pneumonien erwiesen sich Pneumokokken und Pseudomonas spp. mit zusammen $70 \%$ als die häufigsten Erreger [17], daneben muss mit Staphylokokken, Anaerobiern und Enterobakterien gerechnet werden. Patienten mit hämatologischen Neoplasien, insbesondere akuten Leukämien, haben demgegenüber meist schon zu Beginn eine funktionelle Neutropenie; die aggressive antineoplastische Chemotherapie führt zu ausgeprägten Neutropenien von mehreren Wochen bis Monaten. Neben Bakterien sind Pilze häufige Erreger, wobei die invasive pulmonale Aspergillose (IPA) das größte Risiko darstellt.

Ein erhöhtes Risiko für weitere opportunistische Erreger wie Pneumocystis carinii, Cytomegalovirus (CMV), Mycobacterium tuberculosis oder Nocardia asteroides weisen Patienten mit lymphatischen Neoplasien auf. Bei allen übrigen Neoplasien werden diese Erreger vorwiegend aufgrund von Glukokortikoidgaben beobachtet, die im Rahmen der Chemotherapie, antiemetisch oder aus anderer Ursache gegeben werden. Glukokortikoide führen überwiegend zu einer Funktionsstörung der Monozyten und Lymphozyten [18].

\section{Klinik und Differenzialdiagnose}

Das Leitsymptom einer Infektion bei neutropenischen Patienten ist Fieber bzw. subfebrile Temperatur. Dieses sollte neben einer gründlichen klinischen Untersuchung stets Anlass zur Anfertigung einer Röntgenaufnahme der Thoraxorgane sein. Bei Patienten mit hämatologischen Neoplasien sollte bei fehlenden Infiltraten und Nichtansprechen auf eine empirische antimikrobielle Therapie nach $72 \mathrm{~h}$ eine erneute Aufnahme angefertigt werden. Zeigt auch diese keine Infiltrate, sollte eine Computertomographie des Thorax (Spiral- und ggf. HR-CT) durchgeführt werden (Grad II) $[19,20]$. Allgemeinsymptome oder respiratorische Symptome wie Husten, Auswurf, Dyspnoe können vorliegen oder fehlen. Besonders symptomarm verlaufen initial Pilz-Pneumonien. Gelegentlich verlaufen bakterielle Pneumonien, aber auch die Pneumocystis-carinii-Pneumonie (PCP) perakut unter dem Bild einer schweren Sepsis bzw. eines septischen Schocks. Die Differenzialdiagnose zu nichtinfektiösen Infiltraten umfasst u. a. Lungenstauungen, Lungeninfarkte, Hämorrhagien, Atelektasen, medikamenteninduzierte Pneumopathien, organisierende Pneumonien (OP), Alveolarproteinosen und das ARDS. Schließlich muss mit einem pulmonalen Rezidiv der Grunderkrankung gerechnet werden. Es gilt jedoch zu beachten, dass Fieber bei Neutropenie bis zum Beweis des Gegenteils als infektionsbedingt gelten muss.

\section{Diagnostik}

Die Diagnostik beruht zunächst auf einfachen klinischen und radiologischen Grunddaten [21], die eine Einschätzung des Erregerspektrums für die Auswahl der kalkulierten antimikrobiellen Therapie (Tab.4) und eine Entscheidung über den Umfang der weiterführenden Diagnostik erlauben. Die mikrobiologische Basisdiagnostik, die bei jedem Patienten durchgeführt werden sollte, umfasst:

1. zwei Blutkulturen (aerob, anaerob, Pilze). Die Ausbeute ist mit ca. $10-20 \%$ gering, die Spezifität abhängig von korrekter Entnahmetechnik und sorgfältigem Ausschluss extrapulmonaler Infektionsquellen.

2. Sputum (Gram-Färbung zur Beurteilung der Qualität der Probe sowie einer vorherrschenden Bakterien-Spezies, Kultur). Produziert der Patient kein Sputum, kann der Versuch einer Sputuminduktion mit hypertoner $\mathrm{NaCl}$-Lösung gemacht werden. Hierzu liegen keine kontrollierten Studien vor; frühere Untersuchungen zur Sputumdiagnostik zeigten enttäuschende Resultate [22].

3. Nasen-/Rachenabstrich. Dieser erlaubt eine Risikoabschätzung für Infektionen mit bestimmten Erregern (S. viridans, gram-negative Enterobakterien, Pseudomonas spp.), ist jedoch nie beweisend.

4. Urindiagnostik einschl. Legionellen-Antigen im Urin, auch zum Ausschluss extrapulmonaler Infektionen sowie Nachweis einer Candidurie. 
Tab. 4 Differenzialdiagnose pulmonaler Infiltrate bei Neutropenie: Zuordnung des Erregerspektrums zu klinischen und radiologischen Grunddaten

\begin{tabular}{|c|c|c|c|}
\hline Infiltratmuster & Grunderkrankung & Zeitfenster & Wahrscheinliche Erreger \\
\hline \multirow[t]{2}{*}{ lokalisiert/einseitig } & solide Neoplasie & früh $(<10 d)$ & $\begin{array}{l}\text { Streptococcus spp., S. aureus, GNEB, } \\
\text { Pseudomonas spp. }\end{array}$ \\
\hline & hämatologische Neoplasie & spät (> 10d) & $\begin{array}{l}\text { Pilze, resistente GNEB, Pseudomonas spp., } \\
\text { Legionella spp., M. tuberculosis } \\
\text { Nocardia asteroides }\end{array}$ \\
\hline diffus/beidseitig & alle & früh oder spät & $\begin{array}{l}\text { Pneumocystis carinii } \\
\text { CMV, Legionella spp. } \\
\text { Mycobacterium tuberculosis }\end{array}$ \\
\hline
\end{tabular}

Die weiterführende Diagnostik wird empfohlen bei Patienten mit:

1. beidseitigen diffusen Infiltraten. Bei diesen werden gehäuft opportunistische Erreger wie P. carinii und CMV gefunden, seltener auch nichtinfektiöse Ursachen [23].

2. Therapieresistenz, definiert als Nichtansprechen auf die erste bzw. zweite Stufe der kalkulierten oder gezielten antimikrobiellen Therapie. Auch hier besteht eine Erweiterung des Risikospektrums auf seltenere, resistente und opportunistische Erreger sowie nichtinfektiöse Ursachen.

3. schwerer beatmungspflichtiger Pneumonie. Wegen der sehr schlechten Prognose sollten in diesem Kollektiv die diagnostischen Informationen maximal ausgeschöpft werden (Grad III).

Die weiterführende Untersuchung umfasst:

1. CT des Thorax (Spiral- und HR-CT). Aspergillosen, Mykobakteriosen, $\mathrm{PCP}, \mathrm{CMV}$ und einige nichtinfektiöse Lungeninfiltrate weisen in der CT ein charakteristisches, wenn auch nicht spezifisches Befundmuster auf [19,20].

2. Bronchoskopie mit BAL. Der Stellenwert der Bronchoskopie bei Pneumonien unter Neutropenie ist nicht systematisch untersucht. Die Ergebnisse der BAL sind mit einer Ausbeute von $15-60 \%$ variabel [24-28]. Gründe dafür sind antimikrobielle Vorbehandlung, Schwierigkeit der Deutung fakultativ pathogener Mikroorganismen sowie das paravaskuläre Ausbreitungsmuster der Aspergillose. Die Ausbeute ist am höchsten bei nicht-bakteriellen und nicht-mykotischen Erregern wie PCP und CMV, so dass insbesondere bei diffusen Lungeninfiltraten günstige Resultate erzielt werden. Die Indikation kann aufgrund des relativ niedrigen Komplikationsrisikos großzügig gestellt werden, wenn ein Ergebnis mit Konsequenzen für die antimikrobielle Therapie erwartet wird (Grad II) [23]. Eine adäquate Materialaufarbeitung ist sicherzustellen. Über den Wert quantitativer bakterieller Kulturen sind keine kontrollierten Studien verfügbar. Daten aus observationellen Studien sprechen dafür, dass die Erregerquantifizierung mit Signifikanzgrenzen wie bei nosokomialen Pneumonien (BAL: $\geq 10^{4} \mathrm{cfu} / \mathrm{ml}$ ) insbesondere bei nichtvorbehandelten Patienten hilfreich ist [29]. Bei beatmeten Patienten kann bei Verdacht auf bakterielle, mykobakterielle und Pilz-Infektionen auch Tracheobronchialsekret untersucht werden. Hierbei aspirierte Blutkoagel sollten asserviert und mikrobiologisch und histologisch auf Aspergillus spp. untersucht werden. Die postbron- choskopische Verschlechterung des Gasaustausches kann bei Patienten mit vorbestehender grenzwertiger Lungenfunktion und eingeschränktem Gasaustausch eine Intubation und künstliche Beatmung nach sich ziehen. Nach neueren Untersuchungen kann dies bei einem Teil der Patienten durch nichtinvasive Beatmung während der Bronchoskopie vermieden werden [30].

3. Bronchoskopie mit transbronchialer Biopsie (TBB). Diese Methode sollte aufgrund des höheren Risikos (Blutungen, Pneumothorax) nur durchgeführt werden, wenn weniger invasive Methoden erfolglos waren und ein wegweisendes Resultat mit hoher Wahrscheinlichkeit erwartet werden kann. Die diagnostische Ausbeute ist wegen der limitierten Bioptatgröße variabel [31 - 33]. Darüber hinaus hängt die Trefferquote vom röntgenmorphologischen Korrelat (besser bei diffusen Prozessen, schlechter bei Noduli) sowie der Ätiologie ab (paravaskuläres Ausbreitungsmuster der Aspergillose). Die Ausbeute war in einer retrospektiven Studie bei neutropenischen Patienten mit 55\% deutlich höher als bei alleiniger BAL mit 20\%; dies traf insbesondere bei Mykobakteriosen, Pilzinfektionen und Rezidiven der Grunderkrankung zu [33]. Der Quick-Wert sollte $>70 \%$ und die Thrombozytenzahl $>50 \times 10^{12} / \mathrm{ml}$ betragen (Grad III).

4. CT-gesteuerte transthorakale Feinnadelbiopsie (FNAB). Diese Methode bietet sich alternativ zur Abklärung pleuranaher fokaler Infiltrate an, bei denen die Ausbeute der bronchoskopischen Diagnostik gering ist (Grad II) [34]. Hinsichtlich der Gerinnungssituation gelten dieselben Vorgaben wie bei der TBB.

5. Pleurapunktion bei punktablem Pleuraerguss zur klinischchemischen, zytologischen und mikrobiologischen Diagnostik.

6. Offene Lungenbiopsie (OLB). Die OLB stellt die Methode mit der höchsten Aussagekraft, jedoch auch der höchsten assoziierten Morbidität dar. Sie kommt daher erst nach Ausschöpfung aller vorgenannten Methoden zum Einsatz, wenn ein weiterführendes Ergebnis zu erwarten ist. In einer Studie bei 63 Patienten mit hämatologischen Neoplasien wurde in $62 \%$ mittels OLB eine spezifische Diagnose gestellt, wobei in $50 \%$ eine BAL und/oder TBB vorausgegangen war. Bei jeweils einem Drittel lagen Infektionen, Rezidive der Grunderkrankung und inflammatorische Erkrankungen wie die OP vor. Bei Patienten mit spezifischer Diagnose ergaben sich in 69\% therapeutische Konsequenzen [35]. Die Rate an schweren Komplikationen liegt in erfahrenen Zentren unter $5 \%$, wobei die vi- 


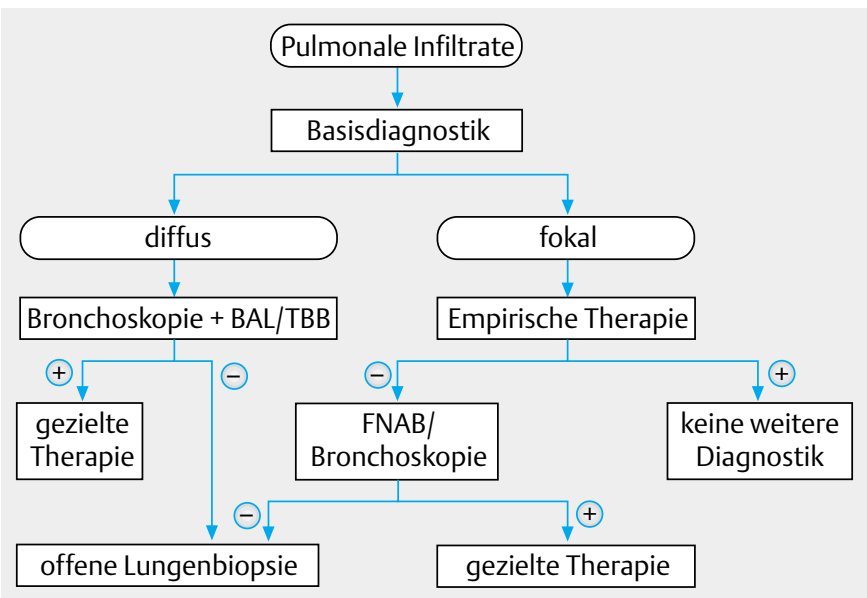

Abb. 1 Algorithmus zur Erregerdiagnostik bei neutropenischen Patienten mit pulmonalen Infiltraten (- negatives Ergebnis; + positives Ergebnis).

deoassistierte Thorakoskopie heute das bevorzugte Verfahren darstellt. Eine adäquate Materialverarbeitung ist wie bei der BAL sicherzustellen. Abb.1 fasst das empfohlene diagnostische Vorgehen bei Patienten mit febriler Neutropenie und Lungeninfiltraten zusammen.

\section{Spezielle Diagnostik von Pilzinfektionen}

Aufgrund der Schwierigkeit der Früherkennung und Diagnosesicherung einer Pilzpneumonie $[36,37]$ finden sich in Tab. 5 die Risikofaktoren und in Tab. 6 die diagnostischen Kriterien für die Pneumonie durch Candida spp. und Aspergillus spp. zusammengefasst. Der kulturelle Nachweis von Aspergillus spp. in Sputum oder BAL beweist zwar keine invasive Infektion, hat aber in Hochrisikosituationen einen prädiktiven Wert von $60-80 \%$ für das Vorliegen einer IPA [37 - 39]. Auch Antigentests auf Aspergillus-Galaktomannan können im Einzelfall die Diagnose einer IPA untermauern [40]. Allerdings ist der zusätzliche Wert dieses Parameters noch unzureichend evaluiert.

\section{Empirische Therapie}

Die Therapieplanung sollte mit der Einschätzung des Schweregrades und der Prognose beginnen. Die Schweregradkriterien entsprechen weitgehend denjenigen der Pneumonie des Immunkompetenten [27]. Bei Patienten mit schwerer Pneumonie muss die Indikation zur Intensivtherapie geprüft werden. Grundsätzlich ist die Prognose bei schwerer Pneumonie unter Neutropenie mit einer Letalität von $80-90 \%$ sowohl bei soliden wie bei hämatologischen Neoplasien sehr ungünstig [41]. Kriterien zugunsten einer Intensivtherapie sind Vorliegen eines kurativen Anspruchs der onkologischen Therapie, eine voraussichtlich limitierte Dauer der Neutropenie sowie der Therapiewunsch des Patienten. Pulmonale Infiltrate unter Neutropenie erfordern eine unverzügliche, breite antimikrobielle Therapie. Während sich bei der unkomplizierten febrilen Neutropenie mit niedrigem Risiko eine antibakterielle Monotherapie sowie primär orale, ambulant applizierbare Therapien als gleichwertig erwiesen haben [18,42], sollte bei Vorliegen pulmonaler Infiltrate wegen der ernsteren Prognose initial stets eine parenterale Kombinationstherapie unter stationärer Überwachung eingesetzt werden (Grad III).
Tab. 5 Risikofaktoren für die Entstehung von Pilz-Pneumonien (modifiziert nach [38])

\section{patientenbezogen}

Immunsuppression durch Kachexie, Diabetes mellitus, Urämie etc.

therapiebezogen

Neutropeniedauer $\geq 10$ Tage

ausgeprägte Mukositis

Kolonisation mit Mykose-Erregern

Immunsuppression durch prolongierte Glukokortikoidtherapie

umweltbezogen

erhöhte Konzentration von Aspergillus-Konidien in der Außenluft (z. B.: Baumaßnahmen, Topfpflanzen, Tierställe, Biotonnen, Kompostierung)

Kontaminierte Nahrungsmittel (z. B.: Fruchtsäfte, Gewürze)

Tab. 6 Diagnostische Kriterien für Candida- und Aspergillus-Pneumonien bei neutropenischen Patienten (modifiziert nach [38])

Candida-Pneumonie
gesicherte Diagnose
- histologischer Nachweis von Hyphen und Pseudohyphen in einer
Lungenbiopsie
- \pm kultureller Nachweis in gleichem Gewebe
Verdachtsdiagnose
- Therapieresistenz trotz breiter antibakterieller Therapie plus Nachweis von Can-
dida spp. in der Blutkultur und/oder in der BAL
- oder plus typische Candida-Endophthalmitis, jeweils erhärtet durch Nachweis
einer Candidurie
Aspergillus-Pneumonie
gesicherte Diagnose
- histologischer Nachweis von Hyphen und Pseudohyphen in einer Lungenbiopsie
- \pm kultureller Nachweis in gleichem Gewebe
Verdachtsdiagnose
- Therapieresistenz trotz breiter antibakterieller Therapie plus Nachweis von As-
pergillus spp. aus Sputum oder BAL
- oder plus Nachweis von Aspergillus-Antigen
- oder plus charakteristische Zeichen einer Aspergillus-Pneumonie in der CT
(Rundinfiltrate mit angiotroper Lage, Halo-Zeichen, „crescent-sign“,
keilförmige Lungeninfarkte, Kavitationen)
- jeweils erhärtet durch typische Klinik: Sinus-Druckschmerz, Thoraxschmerz,
Nasenbluten, Hämoptysen

Zu unterscheiden sind:

1. Pneumonien bei Neutropenie mit einer erwarteten Dauer $<10$ Tage. $\mathrm{Zu}$ dieser Gruppe gehören Patienten mit soliden Tumoren und/oder einer weniger aggressiven Chemotherapie bzw. Patienten mit soliden Tumoren und Hochdosistherapie mit peripherer Stammzelltransplantation. Bei diesen Patienten ist initial eine antibakterielle Kombinationstherapie mit hoher Aktivität gegenüber gram-positiven Kokken, gram-negativen Enterobakterien und Pseudomonas spp. indiziert. Eine zusätzliche antimykotische Medikation ist bei Nichtansprechen gegenüber der ersten antibakteriellen Kombination erforderlich (Grad II) [43].

2. Pneumonien bei Neutropenie mit einer erwarteten Dauer $\geq 10$ Tagen. Es handelt sich meist um Patienten mit hämatologischen Neoplasien und aggressiver Chemotherapie. Zu unterscheiden sind Patienten mit Auftreten der Infektion < 10 Tage nach Beginn der Neutropenie, die initial wie Patienten der ersten Gruppe behandelt werden können, und Patienten mit 
Tab. 7 Antimikrobielle Kombinationstherapie bei Pneumonien unter Neutropenie

\begin{tabular}{|c|c|c|c|}
\hline Basiskombination & & 2. Stufe & 2. -3. Stufe \\
\hline $\begin{array}{l}\text { Acylureidopenicillin (z. B. Piperacillin/Tazobactam) } \\
\text { oder }\end{array}$ & plus Aminoglykosid & $\begin{array}{l}\text { plus Glykopeptid } \\
\text { (Vancomycin, Teicoplanin) }\end{array}$ & plus Amphotericin B* \\
\hline $\begin{array}{l}\text { Acylureidopenicillin (Piperacillin/Tazobactam) } \\
\text { oder }\end{array}$ & plus Ciprofloxacin & & \\
\hline Cephalosporin Gr. 3 b (Ceftazidim, Cefepim) & plus Ciprofloxacin & & \\
\hline
\end{tabular}

* bei Neutropenie $>10 \mathrm{~d} 1$. Stufe

Auftreten der Pneumonie > 10 Tage nach Beginn der Neutropenie; diese benötigen bereits primär eine Kombinationstherapie unter Einschluss einer antimykotischen Medikation (Grad II) [44].

Empfohlene Antibiotikakombinationen sind der Tab. 7 zu entnehmen. Die Substanzauswahl richtet sich nach der KleinraumEpidemiologie der jeweiligen Behandlungseinheit. Unter den Cephalosporinen sollten nur pseudomonaswirksame Substanzen eingesetzt werden. Aminoglykoside sollten vermieden werden bei eingeschränkter Nierenfunktion sowie gleichzeitiger Applikation anderer nephrotoxischer Pharmaka. Die Rolle der Fluorchinolone, unter denen Ciprofloxacin die höchste Aktivität gegen $P$. aeruginosa aufweist, ist weniger gut untersucht. Für ihren Einsatz bei pulmonalen Infiltraten spricht die gute Gewebspenetration. Glykopeptide können bei Verdacht auf unbeherrschte gram-positive Infektionen, Makrolide bei Verdacht auf „atypische“ Erreger, insbesondere Legionellen, zusätzlich gegeben werden.

Bei Verdacht auf Pilzpneumonie unter Neutropenie muss ein breites mykotisches Spektrum abgedeckt werden, so dass für die kalkulierte Therapie bislang nur Amphotericin B infrage kommt (Wirklücken: Candida lusitaniae, Fusarium spp.) (Grad III). Die Kombination mit 5-Flucytosin ist trotz In-vitro-Synergismus gegenüber Hefepilzen der Monotherapie nicht überlegen (Ausnahme: Kryptokokkenmeningitis bei AIDS). Gegen einen Einsatz von 5-Flucytosin spricht darüber hinaus die Toxizität der Substanz (Myelosuppression, seltener hämorrhagische Enterokolitis). Fluconazol und Itraconazol eignen sich nicht zur primären Behandlung von Pilzpneumonien bei Neutropenie, sind jedoch Alternativen bei Amphotericin-B-Unverträglichkeit bzw. in der Erhaltungstherapie.

Zur Therapiedauer liegen keine Daten aus kontrollierten Studien vor. Bei klinischem Ansprechen und fehlenden Hinweisen für eine mykotische Ätiologie kann eine Beendigung der Therapie auch bei fortbestehender Neutropenie nach etwa 10 Tagen erwogen werden (Grad III) [18]. Andernfalls muss für die Dauer der Neutropenie die Behandlung fortgesetzt werden. Individuell ist ein Übergang auf orale Erhaltungstherapien möglich.

\section{Organtransplantation}

\section{Charakterisierung des Immundefizits}

Infolge der zur Organinsuffizienz führenden Grunderkrankung, des operativen Eingriffs und der immunsuppressiven Therapie besteht bei Patienten nach Organtransplantation ein deutlich erhöhtes Risiko, schwer verlaufende pulmonale Komplikationen (in mehr als 90\% Infektionen) zu entwickeln. Deren Inzidenz ist abhängig von der Art der Organtransplantation, der intrinsischen und medikamentösen Immunsuppression, vom Zeitpunkt des Auftretens (zusammengefasst als „Nettostatus“ der Immunsuppression) und von epidemiologischen Faktoren, insbesondere der Intensität der Exposition des Patienten gegenüber obligat bzw. fakultativ pathogenen Keimen [45]. Am höchsten ist die Infektionsrate nach Lungentransplantation, bedingt durch die große Exponiertheit des Organs gegenüber der Umwelt [46]. Abwehrmechanismen der Lunge werden nach Transplantation auf verschiedenen Ebenen gestört [46,47]. Neben der medikamentösen Immunsuppression ist der Hustenreflex durch Denervation der Spenderlunge eingeschränkt, weiter besteht eine Verminderung der mukoziliären Clearance sowie eine Unterbrechung der Lymphdrainage. Die transplantierte Lunge kann infiziert werden durch Transmission einer Infektion des Spenderorgans, durch Erreger aus den oberen Atemwegen oder der verbleibenden Empfängerlunge oder durch Neuinfektion $[48,49]$.

\section{Klinik und Differenzialdiagnose}

Der Nettoeffekt der Immunsuppression beeinflusst wesentlich die Häufigkeit und die Art pulmonaler Komplikationen. So entwickeln ohne CMV-Prophylaxe annähernd 39\% der Patienten nach Herz-Lungen-Transplantation eine symptomatische CMVInfektion, hingegen 29\% nach Lebertransplantation, 25\% nach Herztransplantation und nur $8 \%$ nach Nierentransplantation [50]. Die Inzidenz der invasiven Aspergillose variiert von $1 \%$ bei Nierentransplantierten bis $\mathrm{zu} 9 \%$ bei Lungentransplantierten [51]. Aufgrund der ähnlichen medikamentösen Immunsuppression gibt es allerdings eine gute Übereinstimmung hinsichtlich des Spektrums und zeitlichen Auftretens von Infektionen bei den unterschiedlichen Formen des Organersatzes (Abb. 2). Üblicherweise werden drei Phasen unterschieden: 1. erster Monat nach Organtransplantation, 2. zweiter bis sechster Monat sowie 3. später als 6 Monate nach Transplantation [52]. Die Kenntnis dieses Zeitplans hat klinisch-praktische Konsequenzen, da damit eine Grundlage für einen differenzialdiagnostischen Algorith- 


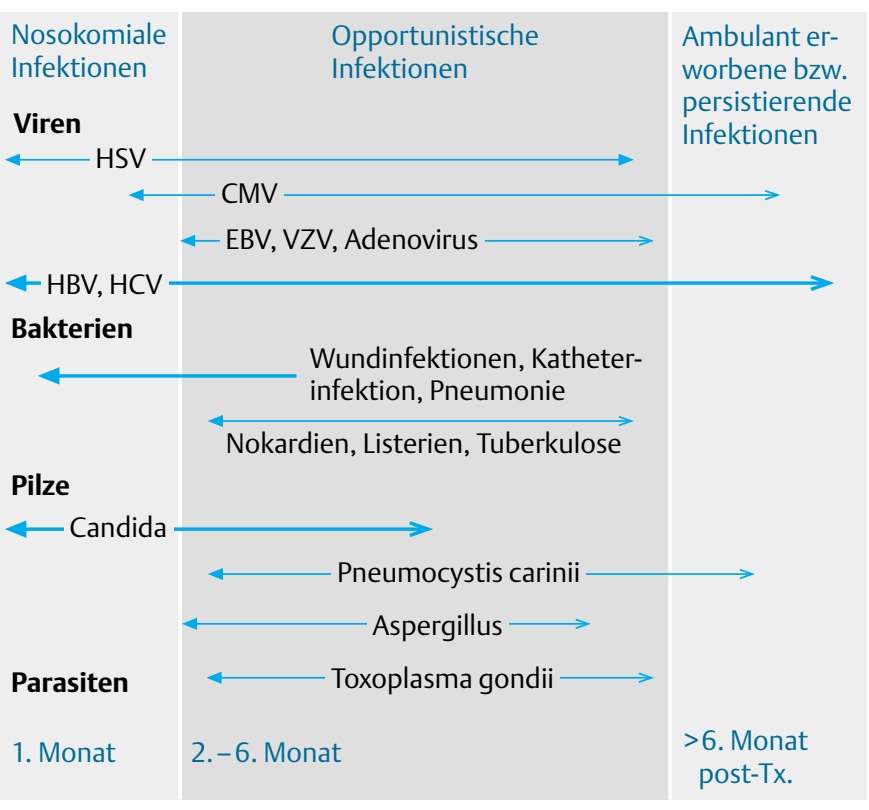

Abb. 2 Zeitlicher Ablauf von Infektionen nach Organtransplantation.

mus besteht und präventive Maßnahmen gezielt erfolgen können.

1. Pulmonale Komplikationen im ersten Monat nach Organtransplantation. In der postoperativen Periode treten Atelektasen, Pleuraergüsse, akutes Lungenversagen und nosokomiale Pneumonien gehäuft auf. Bei über 90\% der Patienten handelt es sich um Infektionen durch nosokomial erworbene Bakterien, wie Staphylokokken und Enterobakterien. Besonders nach Lungentransplantation ist auch mit Pseudomonasinfektionen zu rechnen $[46,47]$. Infektionen durch opportunistische Erreger wie Pilze oder Viren sind selten und sprechen für eine ungewöhnliche Exposition bzw. intensivere Immunsuppression. Eine Sonderform stellt die tracheobronchiale Aspergillose dar, die bevorzugt nach Lungentransplantation auftritt. Diese Infektion befällt insbesondere die Bronchialanastomose und kann zu Dehiszenzen und lebensbedrohlichen Arrosionen großer Gefäße führen [53].

2. Zweiter bis sechster Monat nach Organtransplantation. In dieser Phase treten Komplikationen durch opportunistische Erreger in den Vordergrund. Differenzialdiagnostisch sind vor allem Infektionen durch Viren der Herpesgruppe zu berücksichtigen. Daneben kommen Infektionen durch respiratorische Viren wie Influenza, Respiratory syncytial Virus (RSV) und Adenoviren in Betracht [52]. In Perioden intensivierter Immunsuppression bei Organabstoßung oder im Verlauf von viralen Infektionen werden vermehrt Infektionen durch $P$. $\mathrm{Ca}$ rinii, Toxoplasma gondii, Aspergillus spp., Cryptococcus neoformans und Nocardia spp. beobachtet. Risikofaktor für das Auftreten von CMV-Infektionen ist insbesondere ein CMV-seropositiver Spenderstatus bei CMV-negativem Empfängerstatus. In dieser Subgruppe liegt das Infektionsrisiko ohne Prophylaxe über $70 \%$, und $85 \%$ der Patienten entwickeln eine manifeste CMV-Erkrankung mit hoher Mortalität. Ein weiterer Risikofaktor ist die Verabreichung einer intensivierten immunsuppressiven Behandlung im Rahmen von Abstoßungsreaktionen. CMV-Infektionen bei seropositiven Empfängern eines seropositiven Spenderorgans (Inzidenz: 58\%) oder eines seronegativen Organs (Inzidenz: 69\%) führen bei etwa einem Drittel der Infizierten zur manifesten CMV-Erkrankung [54,55].

3. Pulmonale Komplikationen nach dem sechsten Monat nach Organtransplantation: Grundsätzlich können drei Risikogruppen unterschieden werden [55]. Patienten mit guter Organfunktion und geringer Immunsuppression entwickeln ambulant erworbene Pneumonien mit Erregern wie Pneumokokken, Influenzaviren, Mykoplasmen oder Chlamydien. Das Auftreten von Infektionen durch opportunistische Erreger spricht für eine erhöhte Exposition (z. B. Legionella spp. durch kontaminierte Wasseraufbereitungsanlagen). Die zweite Gruppe stellen Patienten dar, die im Rahmen ihrer Immunsuppression Infektionen durch CMV und andere Herpesviren entwickeln, die sich häufig als generalisierte Infektion mit Lungenbeteiligung manifestieren. Bei einer dritten Gruppe stehen akute oder chronische Abstoßungsreaktionen im Vordergrund. Diese Patienten können aufgrund der intensivierten Immunsuppression Infektionen durch opportunistische Erreger entwickeln. Wechselwirkungen zwischen Infektionen und Abstoßungen werden für die CMV-Infektion diskutiert [54], bei Lungentransplantierten auch für die RSV-Infektion, die in einer Studie mit der Entwicklung einer Bronchiolitis obliterans assoziiert war [56].

Schließlich besteht nach Organtransplantation ein erhöhtes Risiko für das Auftreten von Mykobakterieninfektionen. Eine Tuberkulose manifestiert sich infolge Reaktivierung einer inaktiven Infektion oder seltener infolge De-novo-Infektion in 0,8-1\% der Transplantatempfänger [57,58]. Neben infektiösen Komplikationen sind differenzialdiagnostisch nichtinfektiöse Ursachen von pulmonalen Erkrankungen zu bedenken. Hierzu gehören Lungenödem, Lungeninfarkte, Hämorrhagien, OP, eosinophile Pneumonien oder eine Vaskulitis [59].

\section{Diagnostik}

Die körperliche Untersuchung zielt auf die Klärung der Diagnose und Erfassung der Beeinträchtigung des Patienten durch den Krankheitsprozess. Laboruntersuchungen dienen zur Erfassung sekundärer Komplikationen wie Exsikkose (bei hochfieberhaftem Verlauf), Überwässerung (zum Beispiel bei nierentransplantierten Patienten mit eingeschränkter Transplantatfunktion), Leukopenie und Thrombopenie (bei CMV-Infektion oder medikamenteninduziert) bzw. zum Ausschluss von thromboembolischen Komplikationen.

Indirekte Erregernachweisverfahren, die insbesondere in den Phasen 2 und 3 hilfreich sein können, sind das Aspergillus-Antigen im Serum, Legionella-Antigen im Urin, sowie das pp65-CMV-Antigen im peripheren Blut bzw. die CMV-PCR im Plasma. Die Techniken zum Nachweis einer CMV-Infektion wurden in den letzten Jahren erheblich verbessert. So können heute anstelle des aufwändigen kulturellen Virusnachweises durch Monitoring der Antigenämie oder quantitativen PCR die Wahrscheinlichkeit der Krankheitsmanifestation mit hoher Sensitivität und akzeptabler Spezifität vorhergesagt und hieraus präemptive Therapiestrategien abgeleitet werden. Ein regelmäßiges Monitoring des CMV-Status mit einer der genannten Methoden ist 
daher bei Transplantatempfängern empfehlenswert (Grad II) $[60,61]$.

Zu den direkten Erregernachweisverfahren gehört die mikroskopische und kulturelle Sputumuntersuchung auf aerobe Bakterien, Mykobakterien und Pilze, deren Stellenwert bei unspezifischen Infektionen kaum untersucht ist. Zwei Blutkulturen sollten vor empirischer Therapie unabhängig vom Fieberverlauf entnommen werden (Grad III).

Obwohl mit bildgebenden Verfahren eine Artdiagnose nicht möglich ist, erlaubt die Röntgendiagnostik eine orientierende Zuordnung. So finden sich fokale Konsolidationen eher bei bakteriellen Infektionen, bei subakutem Verlauf auch bei Mykosen, Nokardien- und Mykobakterieninfektionen. Diffuse interstitielle Infiltrate deuten auf Virusinfektionen bzw. eine PCP hin [45]. Allerdings wurden nach Nierentransplantation bei $25 \%$ der Patienten mit diffusen Infiltraten bakterielle Infektionen diagnostiziert [59]. Im Vergleich zur häufig unzureichenden konventionellen Bildgebung erbringt die Computertomographie mit hochauflösender Bildanalyse eine deutlich höhere Sensitivität des Nachweises und Verbesserung der Differenzialdiagnostik von Lungeninfiltraten (Kavitationen, Halo-Zeichen bei Aspergilluspneumonien). Zudem ist sie hilfreich für die Planung transthorakaler Punktionen, so dass die Durchführung der CT in ätiologisch unklaren Fällen empfohlen wird (Grad II) [62].

Aufgrund des breiten differenzialdiagnostischen Spektrums pulmonaler Infiltrate bei organtransplantierten Patienten ist grundsätzlich eine invasive Diagnostik anzustreben [52]. Diese Empfehlung gilt insbesondere für Phasen mit erhöhtem Risiko opportunistischer Infektionen (2.-6. Monat nach Transplantation) sowie bei später auftretenden Infektionen, wenn der Verlauf durch Abstoßungen oder Herpesvirusinfektionen kompliziert ist. Auch bei Patienten mit postoperativer Langzeitbeatmung ist die bronchoskopische Diagnostik oder alternativ das quantitative Trachealaspirat zum Nachweis nosokomialer Erreger empfehlenswert (Grad II) [63].
Die invasive Diagnostik umfasst:

1. Bronchoskopie mit BAL und TBB. Die diagnostische Ausbeute der Bronchoskopie bei transplantierten Patienten ist abhängig von der Art der pulmonalen Komplikation und den gewählten Untersuchungsverfahren und liegt insgesamt zwischen 48 und 55\% $[59,63,64]$. Die Sensitivität der BAL zum Nachweis einzelner Infektionserreger liegt zwischen $48 \%$ für bakterielle Erreger und $>90 \%$ für $P$. carinii [63-65]. Dagegen ist die Ausbeute bei einer invasiven Aspergillose mit 30-50\% deutlich ungünstiger [66]. Die TBB hat eine hohe Sensitivität zum Nachweis einer PCP oder einer CMV-Pneumonie, allerdings können histologische Zeichen einer Infektion oder Abstoßung überlappen. Die Durchführung der transbronchialen Biopsie bei Lungentransplantierten zur Differenzierung von Infektionen und Abstoßungen (routinemäßig bei Verlaufskontrollen oder bei Problemen) wird unterschiedlich gehandhabt. Es liegen keine prospektiven Studien zum Einfluss dieses Vorgehens auf den Krankheitsverlauf vor. Bei medikamenteninduzierter Lungenschädigung bzw. bei interstitiellen Pneumonitiden liegt die Ausbeute der Bronchoskopie aufgrund der unspezifischen histopathologischen Befunde sowie der geringen Größe der Bioptate nur zwischen 40 und 65\% [67-69].

2. Feinnadelpunktion (FNAB). Bei pleuranahen nodulären Infiltraten ist eine transthorakale Feinnadelpunktion vorzuziehen, die CT-gezielt eine hohe diagnostische Ausbeute ergibt (Grad III) [70].

3. Offene Lungenbiopsie (OLB): Eine definitive Diagnose ermöglicht am häufigsten die OLB. Im Vergleich zur TBB (59\%) bzw. FNAB (29\%) lag die Ausbeute in einer Studie bei 94\% [71]. Wegen der erhöhten Morbidität und Mortalität sollte das Verfahren nur nach Ausschöpfung weniger invasiver Verfahren zum Einsatz kommen. Ein Einfluss der Untersuchung auf das Überleben der Patienten konnte bislang nicht nachgewiesen werden. Tab. 8 fasst den empfohlenen Untersuchungsgang in Abhängigkeit von klinischer Konstellation und Zeitpunkt des Auftretens der pulmonalen Komplikation zusammen.

Tab. 8 Untersuchungsgang bei organtransplantierten Patienten mit pulmonalen Komplikationen

\begin{tabular}{|c|c|c|c|}
\hline Radiomorpologie & Symptomatik & wahrscheinliche Ätiologie & Diagnostik \\
\hline homogene Konsolidation & $\begin{array}{l}\text { akut } \\
\text { (nosokomialer Erwerb, Phase } 1>2,3 \text { ) } \\
\text { akut } \\
\text { (ambulanter Erwerb, Phase } 3>2 \text { ) } \\
\text { subakut/chronisch (Phase } 2 \text { und 3) } \\
\text { therapierefraktäres Infiltrat }\end{array}$ & $\begin{array}{l}\text { bakterielle Pneumonie } \\
\text { (S. aureus, GNEB, Pseudomonas spp.) } \\
\text { bakterielle Pneumonie } \\
\text { (S. pneumoniae, H. influenzae) } \\
\text { opportunistische Erreger, nichtinfektiöse } \\
\text { Ursachen } \\
\text { opportunistische Erreger, resistente } \\
\text { Hospitalkeime, nichtinfektiöse Ursachen }\end{array}$ & $\begin{array}{l}\text { Bronchoskopie mit BAL } \\
\text { nichtinvasiv, Sputum oder } \\
\text { Bronchoskopie mit BAL (Phase 2) } \\
\text { Bronchoskopie mit BAL und TBB } \\
\text { HRCT, Bronchoskopie mit BAL und TBB }\end{array}$ \\
\hline diffuse Infiltrate & $\begin{array}{l}\text { akut (Phase } 2>1,3 \text { ) } \\
\text { subakut/chronisch (Phase } 2>1,3 \text { ) }\end{array}$ & $\begin{array}{l}\text { Lungenödem, ARDS, Viren, PCP Viren, } \\
\text { PCP, nichtinfektiöse Ursachen }\end{array}$ & $\begin{array}{l}\text { Bronchoskopie mit BAL und ggf. TBB } \\
\text { Bronchoskopie mit BAL und TBB, HR-CT }\end{array}$ \\
\hline noduläre Infiltrate & $\begin{array}{l}\text { akut/subakut } \\
\text { (alle Phasen) }\end{array}$ & $\begin{array}{l}\text { Pilze (Aspergillus spp.), Nokardien, } \\
\text { Mykobakterien, S. aureus }\end{array}$ & $\begin{array}{l}\text { Bronchoskopie mit BAL und TBB } \\
\text { (zentrale Infiltrate) } \\
\text { CT-gesteuerte Feinnadelaspirationsbiopsie } \\
\text { (pleuranahe Infiltrate) }\end{array}$ \\
\hline
\end{tabular}


Tab. 9 Empirische Therapie pulmonaler Infektionen nach Organtransplantation

\begin{tabular}{|c|c|c|}
\hline Radiomorphologie & $\begin{array}{l}\text { Posttransplantperiode }<30 d \\
\text { (im Krankenhaus erworben) }\end{array}$ & Posttransplantperiode $>30 d$ \\
\hline homogene Konsolidation & $\begin{array}{l}\text { Acylureidopenicillin } \\
\text { oder } \\
\text { Cephalosporin Gr. 3b* } \\
\text { oder } \\
\text { Carbapenem } \\
\text { jeweils plus Fluorchinolon Gr. 2*** } \\
\text { oder Aminoglykosid }\end{array}$ & $\begin{array}{l}\text { Cephalosporin Gr. 2/3a** } \\
\text { oder } \\
\text { Aminopenicillin/Betalactamaseinhibitor } \\
\text { oder } \\
\text { Fluorchinolon Gr. } 3^{* * *}\end{array}$ \\
\hline diffuses Infiltrat & & $\begin{array}{l}\text { Co-trimoxazol }(100 \mathrm{mg} / \mathrm{kg} \text { ) } \\
\text { plus Fluorchinolon Gr. } 2 \\
\pm \text { Ganciclovir (bei v.a. CMV) }\end{array}$ \\
\hline noduläres Infiltrat & $\begin{array}{l}\text { Aminopenicillin/Betalactamaseinhibitor } \\
\text { oder Carbapenem } \pm \text { Amphotericin B }\end{array}$ & \\
\hline
\end{tabular}

${ }^{*}$ Ceftazidim, Cefepim, ${ }^{* *}$ z. B. Cefuroxim, Cefotiam, Cefotaxim, Ceftriaxon, ${ }^{* * *}$ z. B. Ciprofloxacin, ${ }^{* * * *}$ z. B. Levofloxacin

\section{Empirische Therapie}

Die antimikrobielle Therapie sollte unmittelbar nach Materialgewinnung beginnen und auf das erwartete Erregerspektrum gerichtet sein. Tab. 9 zeigt hierzu geeignete Schemata, wobei Daten aus kontrollierten Studien nicht vorliegen (Grad III). Bei nosokomialen Infektionen ist bei einer hohen lokalen Prävalenz von MRSA die zusätzliche Gabe eines Glykopeptids zu diskutieren.

Nach Lungentransplantation ist in der frühen postoperativen Phase bei Verdacht auf Aspiration des Spenders die Auswahl von Substanzen mit guter Anaerobierwirksamkeit (z. B. Penicilline mit Betalaktamaseinhibitor, Carbapeneme) zu empfehlen. Zusätzlich muss die individuelle Resistenzsituation (z.B. Vorhandensein von hochresistenten Pseudomonasstämmen bei Patienten mit zystischer Fibrose) beachtet werden. Fluorchinolone sind meist auch gegenüber Legionellen aktiv, so dass bei Chinolontherapie auf die zusätzliche Gabe eines Makrolidantibiotikums wegen der problematischen Interaktion mit Ciclosporin (Spiegelanstieg) verzichtet werden kann. Ist im Einzelfall die Gabe eines Makrolids nicht zu umgehen, sollte wegen des geringeren Interaktionspotenzials Azithromycin gewählt werden. Häufige Spiegelkontrollen sind erforderlich (Grad II) [72]. Nach Kenntnis der Ätiologie sollte die Behandlung entsprechend den mikrobiologischen Befunden modifiziert werden.

\section{Immunsuppressive Therapie bei Systemerkrankungen}

Systemerkrankungen sind Autoimmunerkrankungen des Bindegewebes und der Gefäße. Wichtigste Vertreter sind die rheumatoide Arthritis, der systemische Lupus erythematodes (SLE), die Sklerodermie, das Sjögren-Syndrom, die Polymyositis/Dermatomyositis, die mikroskopische Polyangiitis, das Churg-StraussSyndrom und die Wegener'sche Granulomatose. Alle Erkrankungen können eine pulmonale Mitbeteiligung aufweisen; beim SLE weisen über $50 \%$ aller Patienten Veränderungen in der Lunge auf [73]. Pulmonale Infektionen sind jedoch die häufigste Komplikation der Systemerkrankung an der Lunge und für bis zu $50 \%$ aller Todesfälle verantwortlich [74]. Randomisierte Studien, die spezifische diagnostische und therapeutische Empfehlungen rechtfer- tigen könnten, existieren nicht. Für die empirische Diagnostik und Therapie müssen daher Erfahrungen bei anderen Immundefizienzen mit herangezogen werden.

\section{Charakterisierung des Immundefektes und Klinik}

Patienten mit Systemerkrankungen haben ein erhöhtes Infektionsrisiko, ohne dass bestimmte Organsysteme bevorzugt sind. Ein verantwortlicher Immundefekt ist nicht identifiziert. Eine Störung der T-Zell/B-Zell-Interaktion wird diskutiert [75]. Bevorzugt treten Infektionen mit bakteriellen Erregern wie Pneumokokken, Staphylokokken und Hämophilus influenzae auf. Wegen der mit einigen Erkrankungen verbundenen Schluckstörungen sind Aspirationspneumonien gehäuft. Schwere Pneumonien werden meist im Zusammenhang mit der immunsuppressiven Therapie beobachtet. Entsprechend den eingesetzten Substanzen, wie Kortikosteroiden, Methotrexat, Cyclophosphamid, Azathioprin, dominieren Infektionen mit Aspergillus spp, Pneumocystis carinii [76], Nokardien [77], Zytomegalievirus [74] und Mykobakterien (überwiegend bei Personen aus Ländern mit hoher Tuberkuloserate unter der Normalbevölkerung) [78]. Neutropenien, die im Rahmen der Grunderkrankung (z.B. SLE, Felty-Syndrom) oder medikamenteninduziert auftreten, prädisponieren für bakterielle und Pilz-Infektionen. Neuerdings wird vermehrt über Infektionen mit Mykobakterien und Pilzen unter Therapie mit TNF-Antikörpern berichtet [79].

\section{Diagnostik}

Ein pathognomonisches Zeichen der pulmonalen Infektion bei Systemerkrankung gibt es nicht [80]. Fieber wird häufig durch die immunsuppressive Therapie gesenkt und kann unter hochdosierter Steroidtherapie ganz fehlen. Ansteigende Entzündungszeichen können sowohl eine Progression der Grunderkrankung als auch eine Infektion anzeigen. Dasselbe gilt für radiologische Infiltrate. Bei Verdacht auf pulmonale Infektion wird daher folgendes Vorgehen empfohlen (Abb. 3):

Zur ambulant durchführbaren Basisdiagnostik gehört das Röntgen-Thoraxbild in 2 Ebenen. Ist es unauffällig, wird eine Lungenfunktionsanalytik mit Spirometrie, Diffusionskapazitätsbestimmung und Blutgasanalytik durchgeführt. Ist diese positiv, wird 


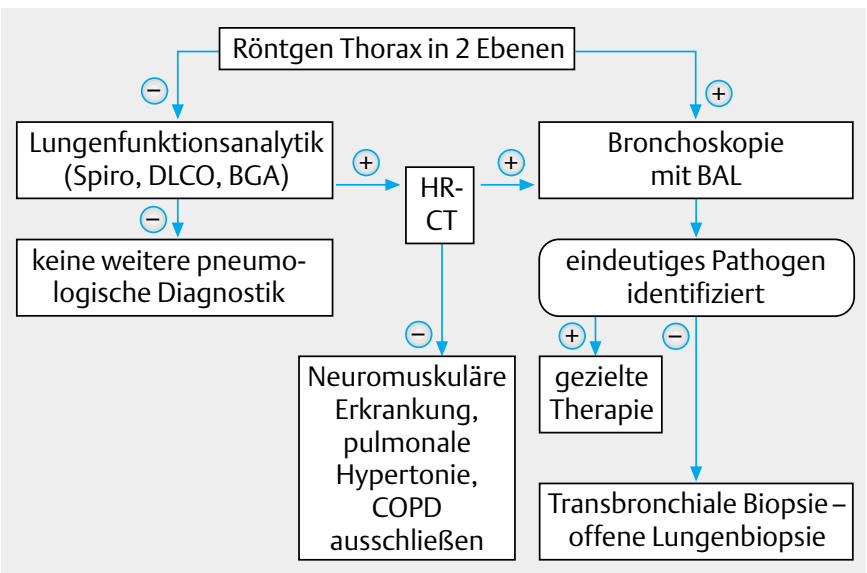

Abb. 3 Algorithmus zur Diagnostik bei Patienten mit Systemerkrankungen und pulmonalen Infiltraten (- negativer Befund; + positiver Befund).

ein HRCT initiiert, da sich bei opportunistischen Infektionen auch ausgeprägte Veränderungen nicht immer im Röntgenbild darstellen [81]. Bei veränderter Lungenfunktion ohne radiologisches Korrelat muss eine krankheits- oder therapieassoziierte (Steroide) Muskelschwäche durch atemphysiologische und elektrophysiologische Untersuchung [82] ausgeschlossen werden. Differenzialdiagnostisch muss eine pulmonale Hypertonie oder eine obstruktive Atemwegserkrankung erwogen werden [74]. Infiltrationen im Röntgenbild oder CT stellen wegen der breiten Differenzialdiagnose eine Indikation zur invasiven Diagnostik dar (Grad III). Hierzu gehört:

1. Bronchoskopie mit BAL. Untersucht wird zytologisch und mikrobiologisch (Bakteriologie inklusive Mykobakteriendiagnostik, Pilzanalytik, CMV, PCP). Eine lymphozytäre Alveolitis spricht eher für pulmonale Mitbeteiligung der Grunderkrankung oder virale Infektion, eine granulozytäre Alveolitis für bakterielle Infektion, ist aber auch mit einer Reihe von Grunderkrankungen wie der PSS oder der Wegener'schen Granulomatose assoziiert. Eine Vermehrung eosinophiler Granulozyten wird bei medikamentenassoziierter Alveolitis oder ChurgStrauss-Syndrom gefunden. Insgesamt ist die Differentialzytologie unspezifisch. Bei der Interpretation der mikrobiologischen Befunde muss zwischen obligat und fakultativ pathogenen Erregern unterschieden werden, da Kolonisation mit fakultativ pathogenen Erregern bei vorgeschädigter Lunge häufig ist.

2. Bioptische Nachweisverfahren. Führen diese Maßnahmen nicht zur Diagnose, müssen Gewebeproben entnommen werden. Transbronchiale Biopsien sind einfacher und komplikationsärmer, die Ausbeute hängt von der Grunderkrankung und dem nachzuweisenden Erreger ab. Offene Lungenbiopsien ergeben eine höhere diagnostische Sicherheit, sind aber mit einem höheren Risiko behaftet [83].

\section{Empirische Therapie}

Die empirische Therapie pulmonaler Infektionen orientiert sich an den individuellen Risikofaktoren des Patienten (Neutropenie, T-Zell-Defizit unter immunsuppressiver Therapie, ambulante vs. nosokomiale Akquisition der Infektion, fokale vs. diffuse Infiltrate). Die Auswahl der Chemotherapeutika folgt den in den Vorkapiteln aufgeführten Kriterien.

\section{HIV-Infektion}

\section{Charakterisierung des Immundefektes}

Die Atemwege stellen das wichtigste Zielorgan für infektiöse Komplikationen bei Patienten mit HIV-Infektion dar. Der zugrunde liegende Immundefekt ist komplex und umfasst stadienabhängig multiple Partialfunktionen des pulmonalen Immunsystems [84]. Im Vordergrund steht der zelluläre Immundefekt mit Abfall der CD4-positiven T-Lymphozyten, der für das erhöhte Erkrankungsrisiko an opportunistischen Infektionen verantwortlich ist. Daneben ist häufig ein Anstieg der zytotoxischen CD8-positiven Lymphozyten in der bronchoalveolären Lavage zu beobachten, der mit unspezifischen interstitiellen Pneumonitiden assoziiert ist [85]. Eine begleitende Phagozytendysfunktion prädisponiert für bakterielle Pneumonien. Schließlich kann eine Verschiebung des Zytokinprofils vom Th1-Typ zum Th2-Typ in fortgeschrittenen Stadien die Infektabwehr gegenüber intrazellulären Erregern zusätzlich beeinträchtigen [86].

Das Infektionsrisiko für einzelne Erreger lässt sich anhand der absoluten Anzahl der CD4-positiven Lymphozyten abschätzen, wobei im Einzelfall mit Abweichungen zu rechnen ist (Abb.4). Während bakterielle Pneumonien und Tuberkulosen in allen Krankheitsstadien gehäuft vorkommen, steigt das Risiko, an einer PCP zu erkranken, ab unterhalb $200 \mathrm{CD} 4-Z e l l e n / \mathrm{mm}^{3}$ deutlich an. Infektionen durch CMV und Mykobacterium-avium/intracellulare-Komplex (MAC) manifestieren sich gehäuft ab CD4-Zellzahlen unter $50 / \mathrm{mm}^{3}$. Durch die Verfügbarkeit effektiver antiviraler Kombinationstherapien (HAART = hochaktive antiretrovirale Therapie) besteht heute die Möglichkeit einer partiellen Immunrekonstitution, so dass sich das Risiko für opportunistische Infektionen normalisiert, wenn die CD4-Zellen unter Therapie für einen Zeitraum von etwa drei Monaten über die genannten Grenzwerte angestiegen sind [87]. Andererseits werden unter Immunrekonstitution teils akute Verschlechterungen von Infektionen wie Tuberkulose, PCP und Zytomegalie beobachtet, die durch den raschen Einstrom immunkompetenter Zellen in die Lunge zu erklären und nicht als Versagen der antimikrobiellen Therapie zu werten sind [88].

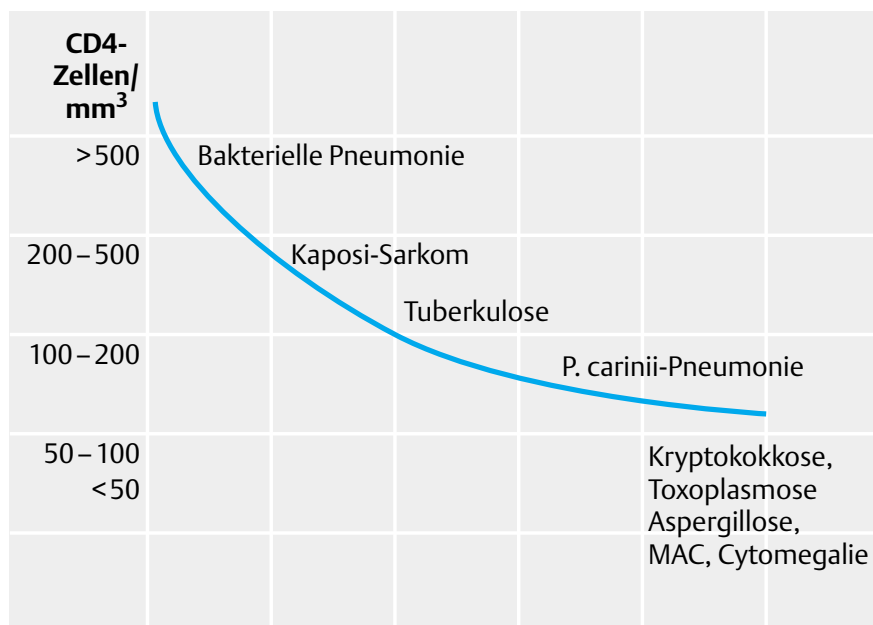

Abb. 4 CD4-Zellzahl und pulmonales Infektionsrisiko bei HIV-Infektion. 


\section{Klinik und Differenzialdiagnose}

Die Ätiologie der Pneumonie bei HIV-positiven Patienten ist infolge verbesserter Therapie- und Prophylaxekonzepte in raschem Wandel begriffen. So ist die Inzidenz der PCP, die zu Beginn der HIV-Epidemie die häufigste pulmonale Infektion darstellte, in Deutschland zwischen 1987 und 1998 von 58\% auf 46\% der AIDS definierenden Erkrankungen zurückgegangen [89], während der Anteil der bakteriellen Infektionen zugenommen hat: diese stehen inzwischen in vielen Studien an erster Stelle [90] (Tab. 10). Insgesamt ist die Inzidenz pulmonaler Infektionen seit Einführung von HAART deutlich gesunken [91].

Tab. 10 Ätiologie von Pneumonien bei HIV-Infektion

\begin{tabular}{|c|c|}
\hline Erreger & Inzidenz [\%] \\
\hline Pneumocystis carinii & $25-40$ \\
\hline $\begin{array}{l}\text { Bakterien } \\
\text { - davon S. pneumoniae } \\
\text { S. aureus } \\
\text { H. influenzae } \\
\text { B. catarrhalis } \\
\text { P. aeruginosa }\end{array}$ & $\begin{array}{cl}40-50 & \\
& 50 \\
& 14 \\
& 12 \\
& 7 \\
& 7\end{array}$ \\
\hline $\begin{array}{l}\text { Mykobakterien } \\
\text { - davon M. tuberculosis } \\
\text { MAC }\end{array}$ & $\begin{array}{l}40-60 \\
20-30\end{array}$ \\
\hline Zytomegalie-Virus & 3 \\
\hline Aspergillus spp. & 2 \\
\hline Cryptococcus neoformans & 1 \\
\hline
\end{tabular}

Bakterielle Pneumonien unterscheiden sich bei HIV-positiven Patienten klinisch und prognostisch nicht signifikant von Infektionen beim immun-kompetenten Wirt. Allerdings liegt häufiger ein symptomarmer Verlauf und eine normale Leukozytenzahl vor [92]. Polymikrobielle Infektionen und Koinfektionen mit $P$. carinii sind mit 10-30\% häufig, was die klinische Beurteilung erschwert [93-96]. Ätiologisch stehen Pneumokokken- und Hämophilusinfektionen im Vordergrund, daneben werden im Vergleich zu immunkompetenten Patienten gehäuft Infektionen mit Staphylococcus aureus, Branhamella catarrhalis und in Spätstadien Pseudomonas spp. gefunden. Bei langsam wachsenden, einschmelzenden Infiltraten ist auch an seltene Erreger wie Rhodococcus equi und Nokardien zu denken.

Die PCP des AIDS-Patienten ist häufig durch einen subakuten Verlauf mit langsam progredienter Dyspnoe gekennzeichnet. In etwa $10 \%$ fällt die Röntgenuntersuchung normal aus, während das CT bereits milchglasartige Verschattungen von landkartenartiger Umgrenzung zeigt und die Spiroergometrie eine eingeschränkte pulmonale Reserve ergibt. Die Patienten klagen über trockenen Husten, der Auskultationsbefund ist selten pathologisch. Die Lungenfunktion ergibt eine respiratorische Partialinsuffizienz mit Diffusionsstörung. Fieber und beidseitige interstitielle Lungeninfiltrate sind Zeichen eines fortgeschrittenen Krankheitsstadiums.

Die Inzidenz der Tuberkulose bei HIV-Infektion hängt von der regionalen TB-Epidemiologie ab. Während weltweit etwa 30-50\% der HIV-Infizierten an Tuberkulose erkranken, werden in

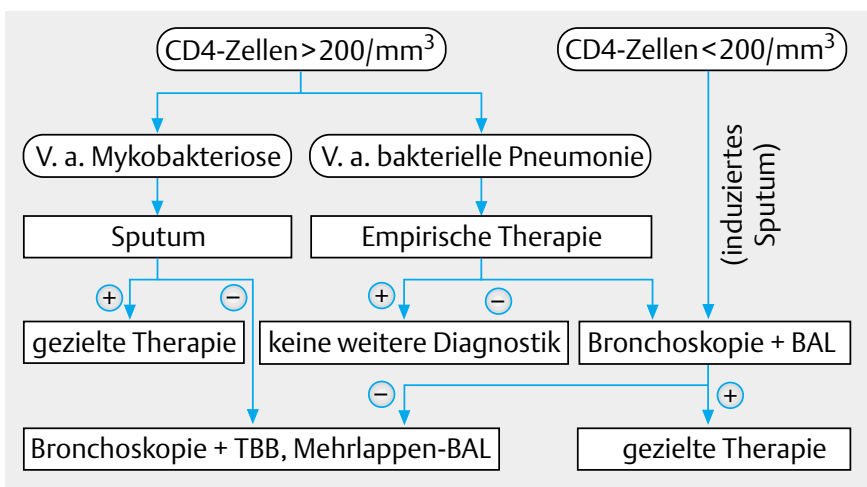

Abb. 5 Algorithmus zur Erregerdiagnostik bei HIV-positiven Patienten mit pulmonalen Infiltraten (- negatives Ergebnis; + positives Ergebnis)

Deutschland wegen der geringen Durchseuchung der Hauptrisikogruppen Koinfektionen seltener beobachtet. Die klinische Manifestation hängt von der Schwere des Immundefizits ab. Bei CD4-Zellzahlen über $100 / \mathrm{mm}^{3}$ finden sich überwiegend Oberlappeninfiltrate mit oder ohne Kavitation. Bei CD4-Zellzahlen unter $100 / \mathrm{mm}^{3}$ werden vermehrt disseminierte und extrapulmonale Verläufe beobachtet. Die Tuberkulintestung ist bei häufig vorliegender Anergie nicht verlässlich. Nicht-tuberkulöse Mykobakteriosen (NTM) können sich als solitäre oder multiple, noduläre Lungeninfiltrate sowie als disseminierte Erkrankungen mit Beteiligung extrapulmonaler Organe präsentieren.

Eine manifeste Zytomegaliepneumonie wird bei AIDS mit 3,5\% aller infektiösen Lungeninfiltrate im Vergleich zu extrathorakalen Manifestationen selten beobachtet, obwohl die Seroprävalenz mit > 90\% hoch und eine Kolonisation der Atemwege häufig ist. Allerdings wurde autoptisch in bis zu $17 \%$ eine pulmonale CMV-Infektion diagnostiziert, so dass die Bedeutung des Erregers in Spätstadien möglicherweise unterschätzt wird $[97,98]$.

Ein erhöhtes Risiko für invasive Aspergillosen besteht im Spätstadium bei Vorliegen zusätzlicher Risikofaktoren wie Neutropenie oder Steroidtherapie [99]. Bei der Kryptokokkose dient die Lunge als Eintrittspforte, während die Prognose durch die zerebrale Manifestation mit aseptischer Meningoenzephalitis beherrscht wird. Bei Infektionen nach Aufenthalten in außereuropäischen Ländern muss auch mit Histoplasmosen gerechnet werden.

\section{Diagnostik}

Die Intensität der Diagnostik richtet sich nach dem erwarteten Erregerspektrum. Abb. 5 zeigt einen stadienadaptierten Algorithmus. In frühen Krankheitsstadien (CD4-Zellzahl über 200/ $\mathrm{mm}^{3}$ ) stehen bakterielle Infektionen im Vordergrund. Nach nichtinvasiver, auch ambulant durchführbarer Basisdiagnostik ist eine empirische Therapie bei begrenztem Erregerspektrum und günstiger Prognose gerechtfertigt, falls kein schwerer, septischer Verlauf vorliegt (Grad II) [96]. Die Basisdiagnostik umfasst die Abnahme von zwei Blutkulturen und die mikroskopische und kulturelle Sputumuntersuchung. Die Bakteriämierate liegt mit 25-60\% höher als bei immunkompetenten Patienten $[95,100]$. Während die Sputumdiagnostik hinsichtlich des Nachweises pyogener Bakterien bei HIV-Infektion unzureichend untersucht ist, stellt sie den Standard bei Verdacht auf Mykobakterieninfek- 
tion dar. Die Bestimmung des Kryptokokken-Antigens im Serum hat einen hohen prädiktiven Wert für den Nachweis der invasiven Kryptokokkose.

In fortgeschrittenen Krankheitsstadien (CD4-Zellzahl $<200 / \mathrm{mm}^{3}$ ) liegt ein erhöhtes Risiko für opportunistische Infektionen wie PCP oder Zytomegalie vor. In dieser Situation wird primär die Durchführung einer bronchoskopischen Diagnostik wegen der höheren Ausbeute bei akzeptabler Patientenbelastung empfohlen (Grad II) [94], auch wenn kontrollierte Untersuchungen im Vergleich zu einem nichtinvasiven Vorgehen fehlen. Hintergrund dieser Empfehlung ist das breite Erregerspektrum und die deutlich höhere Erfolgsrate der invasiven Diagnostik bei nicht vorbehandelten Patienten [101].

1. Bronchoskopie mit BAL. Die Trefferquote liegt bei HIV-positiven Patienten mit Lungeninfiltraten zwischen $55-70 \%$ und steigt auf 80-90\%, wenn alle endoskopischen Techniken einschließlich transbronchialer Biopsie kombiniert werden [94,95,102,103]. Die Ergebnisse sind nach Erregergruppen differenziert zu betrachten: Bei bakteriellen Pneumonien liegt die Sensitivität der BAL bei unvorbehandelten Patienten zwischen 60 und 70\% [94,95,104]. Auch die geschützte bronchoalveoläre Lavage (PBAL) zeigte in einer neueren Studie eine Sensitivität von $68 \%$ beim Nachweis bakterieller Infektionen [105]. Bei diesem Verfahren wird die Lavage über einen bronchoskopisch platzierten Ballonkatheter durchgeführt, der die Kontamination der Spülflüssigkeit durch obere respiratorische Sekrete vermindert. In der Diagnostik der PCP liegt die Sensitivität der BAL bei nicht vorbehandelten Patienten zwischen $85-100 \%$ und kann durch weitere Maßnahmen kaum gesteigert werden. Daher wird die primäre Durchführung der transbronchialen Biopsie mit ihrem höheren Komplikationsrisiko bei Verdacht auf PCP nicht empfohlen (Grad II) [94].

2. Bronchoskopie mit TBB. Bei Patienten unter Chemoprophylaxe gegen $P$. carinii sowie bei negativem Ausfall der Erstdiagnostik ist mit einer niedrigeren Trefferquote der BAL zu rechnen. In diesen Fällen lässt sich die Sensitivität durch Mehrlappenlavage, insbesondere im Oberlappen, und TBB steigern $[103,106]$. Eine weitere Indikation für die TBB besteht bei Verdacht auf Tuberkulose nach negativem Ausfall der mikrobiologischen Diagnostik aus Sputum und BAL. In dieser Situation kann die Biopsie ebenfalls weiterführende Befunde liefern. Bei Verdacht auf IPA oder CMV-Infektion ist die Kombination von BAL und TBB primär anzustreben, da eine sichere Abgrenzung von Kolonisation und invasiver Infektion nur durch den Nachweis der Gewebsinvasivität möglich ist (Grad III) [98].

3. Offene Lungenbiopsie. Offene oder transthorakale Lungenbiopsien sind bei HIV-positiven Patienten wegen der hohen Treffsicherheit der Bronchoskopie sehr selten indiziert. Empfehlungen hierzu können wegen der unzureichenden Datenlage nicht gegeben werden.

Der Einsatz der Sputumuntersuchung in der PCP-Diagnostik wird kontrovers diskutiert. In einer Reihe erfahrener HIV-Zentren ist das induzierte Sputum mit einer Sensitivität von 60-70\% als initiale diagnostische Methode etabliert [107]. Allerdings liegt der negative Vorhersagewert nur bei 39-64\%, so dass bei negativem Befund bronchoskopiert werden muss. Zudem ist die Qualität in hohem Grade untersucherabhängig, und Koinfektionen mit anderen Erregern werden häufig nicht erfasst.
Tab. 11 Initiale Therapie von Pneumonien bei HIV-Infektion

\begin{tabular}{ll}
\hline Stadium & Therapie \\
\hline CD4 $>200 / \mathrm{mm}^{3}$ & Cephalosporin Gr. 2 oder 3a oder \\
& Aminopenicillin $/$ Betalaktamaseinhibitor \\
& \pm Makrolid i.v./p. o. \\
& Co-trimoxazol $100 \mathrm{mg} / \mathrm{kg} / \mathrm{d}$ \\
& In 4 ED i.v. oder p. o. ${ }^{*}$ \\
& \pm Fluorchinolon Gr. 3 \\
\hline
\end{tabular}

* bei $\mathrm{pO}_{2}<70 \mathrm{mmHg}$ adjuvant Glukokortikoide

\section{Empirische Therapie}

Eine empirische Therapie ist unabhängig von Art und Umfang der Diagnostik unverzüglich einzuleiten. Bei Patienten mit CD4-Zellzahlen $>200 / \mathrm{mm}^{3}$ ist, falls kein Verdacht auf eine Mykobakteriose besteht, eine antibakterielle Therapie mit Wirksamkeit gegenüber den häufigsten bakteriellen Erregern wie $S$. pneumoniae, H. influenzae und S. aureus indiziert (Tab. 11). Kontrollierte Studien liegen nicht vor. In Anlehnung an Therapieempfehlungen zur ambulant erworbenen Pneumonie mit Komorbidität kann die Gabe eines Cephalosporins der Gruppe 2 (Cefuroxim, Cefotiam) oder 3a (Cefotaxim, Ceftriaxon) bzw. eines Aminopenicillins mit Betalaktamaseinhibitor empfohlen werden (Grad III) [108]. Die Kombination mit einem Makrolid ist bei regional erhöhter Inzidenz von Legionelleninfektionen empfehlenswert (Grad III). Nach Erhalt positiver Kulturergebnisse kann gezielt weiterbehandelt werden.

Bei Patienten mit CD4-Zellzahlen unter $200 / \mathrm{mm}^{3}$ ist wegen der hohen Inzidenz der PCP eine Initialtherapie mit Aktivität gegenüber bakteriellen Erregern und Pneumocystis carinii erforderlich (Grad II) [90]. Mittel der Wahl ist Co-trimoxazol, das in der zur PCP-Therapie erforderlichen hohen Dosierung viele bakterielle Erreger ebenfalls erfasst. Bei Verdacht auf das Vorliegen Co-trimoxazol-resistenter Erreger wird die Kombination mit einem Chinolon der Gruppe 3 empfohlen (Grad III). Wegen der Toxizität der hochdosierten Co-trimoxazol-Therapie sollte nach Ausschluss einer PCP auf eine gezielte antibakterielle Therapie umgestellt werden. Bei erhöhtem Risiko einer Pseudomonas-Infektion (nosokomialer Erwerb, weit fortgeschrittenes HIV-Stadium, septisches Krankheitsbild) sollte ein Pseudomonas-wirksames Betalaktamantibiotikum gewählt und bei normaler Nierenfunktion mit einem Aminoglykosid kombiniert werden (Grad II) [109].

\section{Gezielte Therapie opportunistischer Infektionen}

\section{Mykobakterieninfektionen Tuberkulose}

Zur gezielten Therapie der Tuberkulose wird auf die Richtlinien des Deutschen Zentralkomitees zur Bekämpfung der Tuberkulose [110] verwiesen; prinzipiell gibt es keine unterschiedlichen Therapiekonzepte zwischen immundefizienten und immunkompetenten Patienten. Allerdings kann eine längere Therapiedauer erforderlich sein, insbesondere wenn die kulturelle Konversion später als drei Monate nach Therapiebeginn eintritt 
Tab. 12 Antimykotische Therapie bei Immundefizit

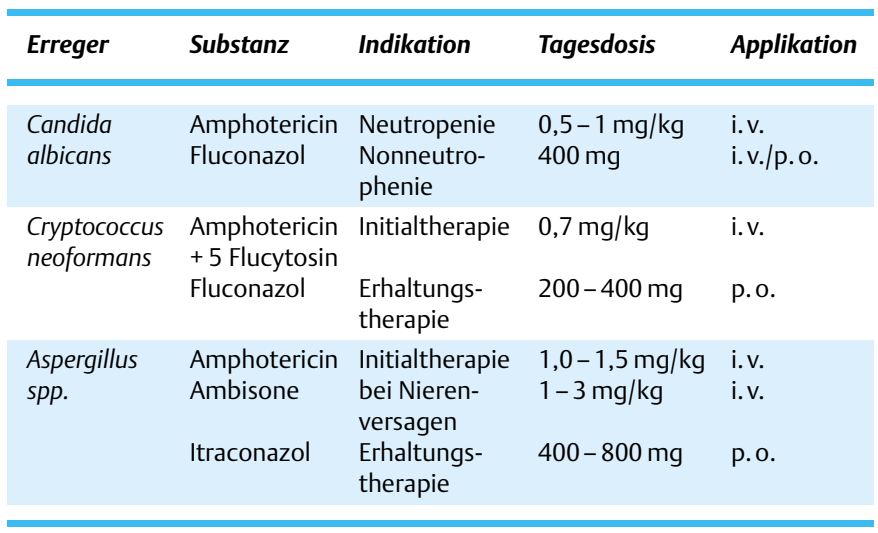

[111]. Bei der Therapie HIV-positiver Patienten sind Interaktionen der Antituberkulotika mit der antiretroviralen Therapie zu beachten. So ist die Kombination von Rifampicin mit nichtnukleosidalen Reversetranskriptase-Inhibitoren (NNRTI) und Proteaseinhibitoren (PI) wegen klinisch relevanter Verminderung der Bioverfügbarkeit kontraindiziert [112] (Grad II). Es wird daher empfohlen, in Fällen mit nicht dringlicher Indikation zur HAART die Tuberkulosetherapie vor Einleitung der antiretroviralen Therapie durchzuführen. Wo dies nicht möglich ist, sollte ein NNRTI- und PI-freies Therapieregime gewählt werden oder Rifampicin durch Rifabutin ersetzt werden, das ein geringeres Interaktionspotenzial aufweist [112] (Grad II). Die Überwachung dieser Therapie einschließlich Medikamentenspiegelbestimmungen sollte in Absprache mit erfahrenen Zentren erfolgen.

\section{Nichttuberkulöse Mykobakterien (NTM)}

Die Therapie von NTM bei immundefizienten Patienten ist von der Grunderkrankung und der isolierten Mykobakterienspezies abhängig. Ein häufig verwandtes und relativ gut verträgliches Regime zur Therapie der MAC-Infektion ist die Kombination von Rifampicin oder Rifabutin, Clarithromycin $(2 \times 500 \mathrm{mg})$ und Myambutol; bei Komedikation mit NNRTI, PI oder Ciclosporin sollte wegen des hohen Interaktionspotenzials auf die Rifamycine verzichtet werden, deren additiver Effekt in einer Studie bei HIV-positiven Patienten gering war [113] (Grad I).

\section{Pilzinfektionen}

\section{Aspergillus und Candida spp.}

Zur gezielten Therapie von Pilzpneumonien bei Immundefizienz sind Amphotericin B und die Azol-Derivate Fluconazol und Itraconazol geeignet. Tab. 12 zeigt Substanzauswahl und Dosierung bei nachgewiesener Pilzinfektion. Wegen der hohen Letalität der invasiven pulmonalen Aspergillose (IPA) muss eine Therapie bereits bei Verdacht eingeleitet werden (Grad II) [43].

Bei Therapie mit Amphotericin sollte vorab eine Testdosis von $1 \mathrm{mg}$ i.v. über 20 min verabreicht werden. Im Anschluss daran (zwei Stunden nach Testdosis) wird mit einer Dosis von 50\% und am Folgetag 100\% der Enddosis therapiert, die in Abhängigkeit von Erregerempfindlichkeit und Schwere der Infektion $0,5-1,5 \mathrm{mg} / \mathrm{kg}$ beträgt. Ein solcher Dosisaufbau ist schonender, jedoch nicht zwingend erforderlich und kann bei einer schweren Mykose unterbleiben. Insbesondere bei der IPA muss primär hoch dosiert und eine kumulative Dosis von 1,5-2 g angestrebt werden [114]. Zur Prävention von Akutreaktionen eignen sich Metamizol (1000 mg per os) oder Pethidin (50-150 mg i.v.) jeweils 30 min vor Beginn der Infusion, eine Nephroprotektion erfolgt durch ausreichende Hydratation, Kochsalzbelastung ( 160 mval $\mathrm{NaCl} 5,85 \%$ über $4 \mathrm{~h}=40 \mathrm{mval} / \mathrm{h}$ ) und Vermeidung nephrotoxischer Komedikation (NSAR, Aminoglykoside, Glykopeptide). Nebenwirkungen umfassen Anämie, Thrombopenie, Hypokaliämie, Nephrotoxizität, Neurotoxizität, Hypotonie, Arrhythmien und Laryngospasmus. Liposomales Amphotericin $B$ kann mit 1-3 (-5) mg/die höher dosiert werden. Diese Darreichungsform ist jedoch nicht gesichert wirksamer, sondern lediglich weniger nephrotoxisch und daher aufgrund der hohen Kosten auf Patienten mit hohem Risiko für eine Nephrotoxizität zu beschränken (Grad I) [115]. Als zusätzliche unerwünschte Wirkung ist mit Rückenschmerzen in Abhängigkeit von der Infusionsgeschwindigkeit zu rechnen. Amphotericin B kann auch prophylaktisch oder additiv als Aerosol angewendet werden. Aus der Stammlösung (50 mg in $10 \mathrm{ml}$ Aqua dest.) werden $2-4 \times /$ die $2 \mathrm{ml}$ über einen Düsenvernebler mit einem Teilchenspektrum von $2-5 \mu$ inhaliert. Über die therapeutische Wirksamkeit liegen keine gesicherten Daten vor.

Fluconazol erzielte bei der Candidämie nichtneutropenischer Patienten in kontrollierten, randomisierten Studien gleichwertige Therapieresultate und kann daher in dieser Indikation bei besserer Verträglichkeit dem Amphotericin vorgezogen werden (Grad I) [116]. Bei Neutropenie liegen dagegen vergleichbare Daten nur aus Beobachtungsstudien vor, Untersuchungen zur Candida-Pneumonie fehlen. Die Substanz ist unwirksam gegenüber Aspergillus spp. und Candida krusei. Die in der Tabelle angegebene Dosierung gilt für $C$. albicans; andere Spezies wie $C$. glabrata sind weniger fluconazolempfindlich und erfordern höhere Dosierungen. Die Inzidenz von C. glabrata-Infektionen ist mit dem Fluconazol-Verbrauch assoziiert [117]. Eine Dosisanpassung bei Niereninsuffizienz ist notwendig; unter Dialyse oder kontinuierlicher Hämofiltration muss die erhebliche extrakorporale Elimination berücksichtigt werden. Mit gastrointestinalen Unverträglichkeiten, Exanthemen, ZNS-Störungen und Hepatotoxizität muss gerechnet werden.

Itraconazol ist auch gegenüber Aspergillus spp. aktiv, wobei sein Einsatz bei der IPA bislang nicht ausreichend gesichert ist. Die Substanz zeigte in unkontrollierten Studien Ansprechraten zwischen 39 und 63\%, wobei Rezidive bei immunkompromittierten Patienten häufiger waren [118]. Die Lösung weist eine bessere Bioverfügbarkeit als die Kapselform auf. Itraconazol hat seinen Stellenwert derzeit vor allem bei Patienten mit Kontraindikationen gegen Amphotericin sowie in der oralen Anschlusstherapie (Grad III); wegen der variablen Resorption der Substanz sollten Serumspiegelkontrollen erfolgen (Grad II). Eine intravenöse Applikationsform ist seit kurzem verfügbar. Die Nebenwirkungen sind denen des Fluconazol vergleichbar, relevante Interaktionen betreffen Medikamente, die über das Cytochrom-P450-System metabolisiert werden.

Weitere, vom pharmakologischen Profil her interessante Substanzen zur Therapie systemischer Mykosen sind Caspofungin 
Tab. 13 Therapie der Pneumocystis carinii - Pneumonie

\begin{tabular}{|c|c|c|c|c|c|}
\hline Klinik & Substanz & Tagesdosis & Einzeldosen/d & Applikation & Therapiedauer (d) \\
\hline mittelschwer/schwer & $\begin{array}{l}\text { Co-trimoxazol } \\
\text { Pentamidin }\end{array}$ & $\begin{array}{l}90-120 \mathrm{mg} / \mathrm{kg} \\
3-4 \mathrm{mg} / \mathrm{kg}\end{array}$ & $\begin{array}{l}4 \\
1\end{array}$ & $\begin{array}{l}\text { i.v./p.o. } \\
\text { i.v. }\end{array}$ & $\begin{array}{l}21 \\
21\end{array}$ \\
\hline $\begin{array}{l}\mathrm{pO}_{2}<70 \mathrm{~mm} \mathrm{Hg} \\
\text { in Ruhe }\end{array}$ & $\begin{array}{l}\text { Prednison } \\
\text { (Adjuvant) }\end{array}$ & $\begin{array}{l}80 \mathrm{mg} \\
40 \mathrm{mg} \\
20 \mathrm{mg}\end{array}$ & $\begin{array}{l}2 \\
1 \\
1\end{array}$ & $\begin{array}{l}\text { p.o. } \\
\text { p.o. } \\
\text { p.o. }\end{array}$ & $\begin{array}{l}\text { 1.-3.d } \\
\text { 4.-6. } d \\
\text { 7.-9.d }\end{array}$ \\
\hline
\end{tabular}

und Voriconazol. Da die klinischen Erfahrungen begrenzt sind [119,120], können noch keine Empfehlungen zum Einsatz bei pulmonalen Pilzinfektionen abgegeben werden.

Bei Patienten mit lokal begrenzter IPA ist die chirurgische Resektion als zusätzliche therapeutische Option zu diskutieren. Mögliche Indikationen sind Hämoptysen bei zentraler Lokalisation, ohnehin bestehende diagnostische Indikation zur OLB und prolongiertes Neutropenierisiko (z.B. Zustand vor Knochenmarkstransplantation) (Grad III) [121].

\section{Pneumocystis carinii}

Zur Therapie der mittelschweren bis schweren PCP $\left(\mathrm{pO}_{2}<70\right.$ $\mathrm{mmHg}$ in Ruhe) stehen Co-trimoxazol und Pentamidin zur Verfügung (Tab. 13). Co-trimoxazol sollte bei Fehlen von Kontraindikationen bevorzugt werden, weil es in einer randomisierten, kontrollierten Studie gegenüber parenteralem Pentamidin mit einer niedrigeren Mortalität assoziiert war (Grad I) [122]. Beide Regimes sind mit einer hohen Nebenwirkungsquote behaftet, ein Therapiewechsel ist bei $20-57 \%$ der Patienten erforderlich $[122,123]$. Unter Co-trimoxazol ist mit Allergie, Myelosuppression, Nieren- und Lebertoxizität zu rechnen. Von einer begleitenden Folinsäuregabe ist abzuraten, nachdem eine klinische Studie hierunter eine erhöhte Mortalität ergab (Grad II) [124]. Die unerwünschten Wirkungen von Pentamidin umfassen Niereninsuffizienz, Leukopenie, akute Pankreatitis, Hypoglykämien und Kardiotoxizität. Inhalatives Pentamidin weist ein günstiges Nebenwirkungsprofil auf, ist aber weniger effektiv und daher im Regelfall nicht einsetzbar [125]. Alternativ kommen zur Therapie der milden bis mäßiggradigen PCP Dapson/Trimethoprim und Atovaquone in Betracht (Grad I) [123,126]. Dapson/Trimethoprim erwies sich in einer randomisierten Studie gegenüber Co-trimoxazol bei geringerer Toxizität als gleichwertig. Allerdings muss ein Glukose-6-Phosphatdehydrogenasemangel ausgeschlossen werden, der zu Hämolysen disponiert [126]. Atovaquone war in einer kontrollierten Studie zur Therapie der leichten bis mittelschweren PCP mit einer höheren Mortalität assoziiert als Co-trimoxazol [123]. Eine Indikation ergibt sich derzeit bei Kontraindikationen gegenüber den vorgenannten Substanzen. Eine weitere, vor allem in den USA etablierte Alternative zur Behandlung der leichten bis mittelschweren PCP ist die Kombination von Primaquin und Clindamycin.

Bei mittelschwerer bis schwerer PCP mit einem $\mathrm{pO}_{2}<70 \mathrm{~mm} \mathrm{Hg}$ ist die adjuvante Gabe von Glukokortikoiden in der in Tab.13 aufgeführten Dosierung indiziert (Grad I) [127]. Diese Therapie hat in mehreren unkontrollierten und einer kontrollierten Studie bei AIDS-Patienten deutliche Vorteile hinsichtlich Morbidität und Mortalität gezeigt. Bei HIV-negativen Patienten mit PCP liegen keine kontrollierten Studien vor. Retrospektive Analysen weisen darauf hin, dass auch in diesem Kollektiv die Kortikoidgabe vorteilhaft sein könnte [128].

Eine klinische Besserung der PCP ist erst nach 3-5-tägiger Therapie zu erwarten, so dass eine Beurteilung des Therapieerfolgs früher nicht möglich ist. Ein Umsetzen wegen Therapieversagens sollte also erst nach 5 Tagen erfolgen (Grad III). In der BAL finden sich unter Therapie häufig noch Pneumozysten, so dass dieser Befund nicht für mangelnden Therapieerfolg spricht. Allerdings sollte die Erregerdichte im Verlauf abnehmen. Zur Therapiedauer existieren keine Daten aus randomisierten Studien. In der Regel wird eine Behandlung über 21 Tage empfohlen (Grad III), auch wenn einige Therapeuten wegen des kumulativ steigenden $\mathrm{Ne}-$ benwirkungsrisikos 14-tägige Regimes vorziehen. Bei Umsetzen nach Therapieversagen sollte mindestens zwei weitere Wochen behandelt werden, um Rezidive zu vermeiden (Grad III).

\section{Herpesvirusinfektionen}

Zur Therapie der Herpesvirusinfektionen stehen die Nukleosidanaloga Aciclovir und Ganciclovir, das Phosphonatanalogon Foscarnet und neuerdings das Cidofovir zur Verfügung. Die Empfehlungen zur gezielten Therapie basieren auf Erfahrungen in der Behandlung extrapulmonaler Manifestationen, da kontrollierte Studien zur Therapie pulmonaler Infektionen fehlen (Tab.14). Bei HSV- und VZV-Infektionen ist Aciclovir wegen der geringeren Nebenwirkungsrate vorzuziehen; eine Dosisanpassung bei Niereninsuffizienz ist erforderlich. Bei Resistenzen, die nach häufigen Vorbehandlungen bei Patienten mit AIDS auftreten, ist alternativ Foscarnet einzusetzen; das Nebenwirkungsspektrum der Substanz umfasst u.a. Nephrotoxizität, Pankreatitis, Hypoglykämie, Hypokalzämie.

Standardsubstanz zur Therapie der Zytomegalie ist Ganciclovir, das bei systemischen CMV-Infektionen Ansprechraten von $70-80 \%$ zeigte $[129,130]$. Nebenwirkungen umfassen Myelosuppression, Nierenfunktionsstörungen und Azoospermie. Bei Therapieversagen oder Kontraindikationen kann ebenfalls auf Foscarnet ausgewichen werden, das in kontrollierten Studien vergleichbare Ansprechraten zeigte [129]; dagegen sind die klinischen Erfahrungen mit Cidofovir begrenzt. Neuerdings steht als oral applizierbares Derivat Valganciclovir zur Verfügung, das in einer randomisierten Studie zur CMV-Retinitis in der Initial- 
Tab. 14 Therapie von Herpesvirusinfektionen bei Immundefizit

\begin{tabular}{|c|c|c|c|c|c|c|}
\hline Erreger & Indikation & Substanz & Tagesdosis & Einzeldosen & Applikation & Therapiedauer (d) \\
\hline Zytomegalievirus & Initialtherapie & $\begin{array}{l}\text { Ganciclovir } \\
\text { Foscarnet } \\
\text { ( } \pm \text { CMV-Hyperimmunglobulin) }\end{array}$ & $\begin{array}{l}10 \mathrm{mg} / \mathrm{kg} \\
180 \mathrm{mg} / \mathrm{kg} \\
(5-10 \mathrm{~g} / \text { Woche })\end{array}$ & $\begin{array}{l}2 \\
2-3\end{array}$ & $\begin{array}{l}\text { i.v. } \\
\text { i.v. }\end{array}$ & $\begin{array}{l}14 \\
14\end{array}$ \\
\hline & $\begin{array}{l}\text { Suppressionstherapie } \\
\text { Reserve }\end{array}$ & $\begin{array}{l}\text { Ganciclovir } \\
\text { Foscarnet } \\
\text { Cidofovir }\end{array}$ & $\begin{array}{l}5 \mathrm{mg} / \mathrm{kg} \\
90-120 \mathrm{mg} / \mathrm{kg} \\
5 \mathrm{mg} / \mathrm{kg} 1 \times / 7-14 d\end{array}$ & $\begin{array}{l}1 \\
1-2 \\
1\end{array}$ & $\begin{array}{l}\text { i.v. } \\
\text { i.v. } \\
\text { i.v. }\end{array}$ & $\begin{array}{l}14-21 \\
14-21\end{array}$ \\
\hline Herpes-simplex-Virus & $\begin{array}{l}\text { Initialtherapie } \\
\text { Acv Resistenz }\end{array}$ & $\begin{array}{l}\text { Aciclovir (Acv) } \\
\text { Foscarnet }\end{array}$ & $\begin{array}{l}15 \mathrm{mg} / \mathrm{kg} \\
180 \mathrm{mg} / \mathrm{kg}\end{array}$ & $\begin{array}{l}3 \\
2-3\end{array}$ & $\begin{array}{l}\text { i.v./p.o. } \\
\text { i.v. }\end{array}$ & $\begin{array}{l}10 \\
10\end{array}$ \\
\hline Varizella-Zoster-Virus & $\begin{array}{l}\text { Initialtherapie } \\
\text { bei Acv-Resistenz }\end{array}$ & $\begin{array}{l}\text { Aciclovir } \\
\text { Foscarnet }\end{array}$ & $\begin{array}{l}30 \mathrm{mg} / \mathrm{kg} \\
180 \mathrm{mg} / \mathrm{kg}\end{array}$ & $\begin{array}{l}3 \\
2-3\end{array}$ & $\begin{array}{l}\text { i.v. } \\
\text { i.v. }\end{array}$ & $\begin{array}{l}10 \\
10\end{array}$ \\
\hline
\end{tabular}

therapie ebenso gut wie parenteral verabreichtes Ganciclovir abschnitt [131].

\section{Prävention respiratorischer Infektionen bei Immundefizit}

Prophylaktische Maßnahmen sind bei immunkompromittierten Patienten angesichts der teils sehr schweren Verläufe von Infektionen in Abhängigkeit von Art und Ausmaß des Immundefizits sinnvoll. Ziel ist die Verhinderung der Erstmanifestation häufiger infektiöser Komplikationen (Primärprophylaxe) bzw. die Reduktion des Risikos einer Reinfektion (Sekundärprophylaxe). Von der eigentlichen Prophylaxe unterschieden wird die präemptive Therapie. Hierunter wird die Verabreichung von antimikrobiellen Substanzen bei Patienten mit einem hohen Risiko für eine bestimmte Infektion vor Auftreten klinischer Infektzeichen verstanden. Das Risiko kann auf der Basis von Surrogatmarkern definiert sein bzw. aufgrund einer hohen epidemiologischen Wahrscheinlichkeit, dass sich eine bestimmte Infektion im weiteren Verlauf entwickeln wird. Nach Organtransplantation ist die Inzidenz pulmonaler Infekte bei Lungenempfängern am höchsten. Die Prophylaxe nach Transplantation soll deshalb schwerpunktmäßig anhand dieses Immundefizits dargestellt werden. Die Wahrscheinlichkeit einer Infektion wird wesentlich von der Art und Intensität der Immunsuppression bestimmt und ist im ersten Jahr nach Transplantation sowie in Phasen augmentierter immunsuppressiver Therapie bei Abstoßungsbehandlungen am größten. In den Transplantationszentren haben sich empirische Strategien der Infektionsprophylaxe etabliert, die allerdings fast ausschließlich historisch begründet sind. Im Gegensatz hierzu leiten sich die Erfahrungen in der Prophylaxe respiratorischer Infektionen bei Patienten mit HIV-Infektion überwiegend aus kontrollierten prospektiven Studien ab. Diese Empfehlungen wurden in den letzten Jahren wesentlich überarbeitet, nachdem parallel zur Einführung hochaktiver antiretroviralen Kombinationstherapien (HAART) ein Rückgang aller opportunistischer Infektionen um über 50\% erreicht werden konnte [87]. Zur Infektionsprophylaxe unter Neutropenie wird auf aktuelle Empfehlungen der onkologischen Fachgesellschaften verwiesen [132].

\section{Bakterien}

\section{Postoperative Pneumonien}

Die Prävalenz bakterieller Pneumonien nach Lungen- und HerzLungentransplantation beträgt fast $35 \%$. Am häufigsten werden diese Infektionen durch Staphylokokken und gramnegative Bazillen, insbesondere $P$. aeruginosa und $S$. aureus verursacht [133] Eine perioperative antimikrobielle Prophylaxe, die dieses Erregerspektrum berücksichtigt, vermag die Pneumonie-Rate auf ca. $10 \% \mathrm{zu}$ senken. Eine spezielle Pseudomonas-Prophylaxe wird durchgeführt, wenn nach Absetzen der perioperativen Antibiotikatherapie eine Keimbesiedlung des Bronchialsystems persistiert. Dies ist nahezu regelhaft bei Patienten mit zystischer Fibrose, gelegentlich auch bei anderen Bronchiektasenerkrankungen der Fall. Inhalativ kommen Tobramycin oder Colistin zum Einsatz. Die Therapie wird mindestens bis zum Abheilen der Bronchialanastomose fortgesetzt (Grad III). Patienten, die im weiteren Verlauf eine Bronchiolitis obliterans entwickeln, weisen häufig eine sekundäre Besiedlung ihres Bronchialsystems mit Pseudomonaden auf. Hier hat sich eine inhalative Therapie mit Aminoglykosiden bewährt (Grad III).

\section{Pneumokokken-Pneumonie}

Pneumokokken sind die häufigsten Erreger bakterieller Pneumonien bei Patienten mit HIV-Infektion [93]; bei organtransplantierten Patienten sind sie bei ambulantem Erwerb der Infektion ebenfalls von Bedeutung. Eine sinnvolle Expositionsprophylaxe kann nicht empfohlen werden. Die Schutzimpfung wird von der ständigen Impfkommission am Robert Koch-Institut u. a. für Immundefizienz, HIV-Infektion, Asplenie, vor Beginn einer immunsuppressiven Therapie und vor Organtransplantation empfohlen. Der zur Zeit verfügbare Impfstoff besteht aus einem Kapselpolysaccharidgemisch von 23 Pneumokokken-Serotypen, die ca. 85-90\% aller humanpathogenen Pneumokokkentypen beinhalten. Eine Auffrischung sollte nach 5-6 Jahren erfolgen (Tab. 15). Bei HIV-Infektion wird jedoch ein schnellerer Abfall des Antikörpertiters beobachtet, so dass Auffrischimpfungen alle 3-5 Jahre notwendig werden. Dies gilt insbesondere, wenn die Erstimp-

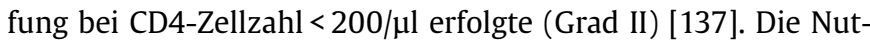
zen- und Kosteneffektivität der Impfung in fortgeschrittenen Krankheitsstadien ist umstritten. Bei geplanter Organtransplantation sollte die Impfung vor Registrierung auf der Warteliste er- 
Tab. 15 Chemoprophylaxe von Infektionen bei erworbener Immundefizienz

\begin{tabular}{|c|c|c|c|}
\hline Erreger & Zielgruppe & 1. Wahl & Alternativen \\
\hline Pneumokokken & $\begin{array}{l}\text { organtransplantiert; Asplenie } \\
\text { HIV-infiziert, Immundefizit }\end{array}$ & Pneumokokken-Impfung alle 5 Jahre & \\
\hline M. tuberculosis & $\begin{array}{l}\text { bei Immundefizienz; } \\
\text { HIV-infiziert mit positivem Tuberkulintest; } \\
\text { positive Umgebungsanamnese (Empfeh- } \\
\text { lungen der CDC; Indikationsabwägung } \\
\text { s. Text) }\end{array}$ & $\begin{array}{l}\text { INH } 300 \text { mg/d + Pyridoxin } 50 \text { mg/d oder } \\
\text { INH } 900 \text { mg + } 100 \text { mg Pyridoxin } 2 \times \text { wö- } \\
\text { chentlich, jeweils für } 9 \text { Monate (DOT); } \\
\text { oder Rifampicin } 600 \text { mg + PZA } 20 \text { mg/kg/d } \\
\text { für } 2 \text { Mo. }\end{array}$ & $\begin{array}{l}\text { Rifabutin } 300 \mathrm{mg} / \mathrm{d}+\text { PZA } 20 \mathrm{mg} / \mathrm{kg} \text { für } \\
2 \text { Monate; oder Rifampicin } 600 \mathrm{mg} / \mathrm{d} \text { für } \\
4 \text { Monate }\end{array}$ \\
\hline M. avium complex (MAC) & HIV-infiziert mit CD4+-Zellzahl $<50 / \mu \mid$ & $\begin{array}{l}\text { Azithromycin } 1200 \mathrm{mg} 1 \times / \text { Woche; oder } \\
\text { Clarithromycin } 2 \times 500 \mathrm{mg} / \mathrm{d}\end{array}$ & $\begin{array}{l}\text { Rifabutin } 300 \text { mg/d; oder Azithromycin } \\
1200 \text { mg 1x/Woche + Rifabutin } 300 \text { mg }\end{array}$ \\
\hline Cytomegalie-Virus & $\begin{array}{l}\text { Hochrisiko (Organtransplantation mit } \\
\text { CMV-Mismatch) } \\
\text { Normalrisiko }\left(\mathrm{D}^{+} / \mathrm{R}^{+}\right)\end{array}$ & $\begin{array}{l}\text { Ganciclovir } 5-6 \mathrm{mg} / \mathrm{kg} 5-7 \times / \text { Woche i.v. } \\
\text { oder } 3 \times 1000 \mathrm{mg} / \mathrm{d} \text { p. o. } \\
\text { Ganciclovir } 5-10 \mathrm{mg} / \mathrm{kg} / \mathrm{d} \text { über } 7-14 \mathrm{~d}\end{array}$ & Foscavir $90-120 \mathrm{mg} / \mathrm{kg} / \mathrm{d}$ i.v. \\
\hline Influenza A & $\begin{array}{l}\text { organtransplantiert; } \\
\text { HIV-infiziert, Immundefizit }\end{array}$ & jährliche Influenza-Impfung & Amantadin $2 \times 100 \mathrm{mg} / \mathrm{d}$ \\
\hline Herpes Simplex-Virus & lungentransplantiert & $\begin{array}{l}\text { Aciclovir } 4 \times 200 \mathrm{mg} / \mathrm{d} \\
\text { (nicht zusätzlich zu Ganciclovir) }\end{array}$ & \\
\hline Pneumocystis carinii & $\begin{array}{l}\text { HIV-infiziert und CD4+-Zellen }<200 / \mu \mathrm{l} \text {; } \\
\text { 1. - } 6 \text {. Monat oder länger nach Lungen- } \\
\text { transplantation unter intensiver medika- } \\
\text { mentöser Immunsuppression }\end{array}$ & $\begin{array}{l}\text { Cotrimoxazol } 480-960 \mathrm{mg} / \mathrm{d} \text {; oder } 960 \mathrm{mg} \\
3 \times \text { pro Woche }\end{array}$ & $\begin{array}{l}\text { Pentamidin p.inh. } 300 \mathrm{mg} 1 \times / \text { Monat oder } \\
\text { Dapson } 100 \mathrm{mg} / \mathrm{d} \text {; oder Dapson } 50 \mathrm{mg} / \mathrm{d}+ \\
\text { Pyrimethamin } 50 \mathrm{mg} 1 \times / \text { Woche }\end{array}$ \\
\hline
\end{tabular}

folgen. Eine Impfung gegen Haemophilus influenzae Typ b (HIB) ist wegen der geringen Inzidenz dieser Infektion bei Erwachsenen nicht generell sinnvoll.

\section{Asplenie}

Aufgrund der hohen Morbidität und Mortalität bakterieller Infektionen in diesem Kollektiv ist eine Primär- und Sekundärprophylaxe erforderlich, die mit einer Impfung gegen Pneumokokken [138] und HIB und/oder mit einer dauerhaften Verabreichung von Antibiotika erfolgen kann. Kontrollierte Studien zu diesen Ansätzen liegen nicht vor, so dass den derzeitigen Empfehlungen eine fundierte wissenschaftliche Evidenz fehlt [138 - 140]. Kinder unter 6 Jahren werden als gefährdeter angesehen; für diese Altersgruppe wird eine Kombination der Impfungen mit einer antibiotischen Prophylaxe von den meisten Autoren gefordert. Ältere Kinder und Erwachsene sollten gegen Pneumokokken und HIB geimpft werden; eine Antibiotikaprophylaxe wird nur bei erhöhtem Infektionsrisiko (hämatologisch/ onkologische Grunderkrankung) als indiziert angesehen (Grad III). Impfungen sollten mindestens zwei Wochen vor elektiver Splenektomie erfolgen, da die Antikörperantwort nach Splenektomie abgeschwächt ist [141]. Eine Antibiotikaprophylaxe sollte bei jüngeren Kindern zumindest über die ersten 2 Jahre bzw. bis zum Abschluss des 6. Lebensjahres durchgeführt werden; als Präparate werden Penicillin V, Ampicillin oder Cephalosporine eingesetzt, wobei die beiden letztgenannten Gruppen den Vorteil einer zusätzlichen Hämophilus-Aktivität haben (Grad III).

\section{Mykobakterien}

\section{Mycobacterium tuberculosis}

Das relative Risiko von Tuberkuloseerkrankungen ist bei HIV-Infizierten, nach Organtransplantation und unter chronischer Therapie mit Glukokortikoiden ( $>15 \mathrm{mg}$ Prednisonäquivalent/d für eine Dauer $\geq 4$ Wochen) gegenüber Gesunden erhöht [142]. In der Mehrzahl der Fälle handelt es sich um Reaktivierungen. Das Reaktivierungsrisiko liegt bei einem HIV-Infizierten etwa 6-100fach höher als bei nicht-infizierten Personen. In den USamerikanischen Empfehlungen der „Centers for Disease Control“ (CDC) wurde deshalb die in Deutschland verwandte Nomenklatur „Chemoprophylaxe“ und „Prävention“ durch die Bezeichnung „Behandlung einer latenten Infektion“ ersetzt [142]. Es gibt bei HIV-Infizierten aber auch eine überraschend hohe Rate an Neuinfektionen. Genetische Erregeranalysen haben gezeigt, dass bis zu 30\% der Tuberkuloseerkrankungen in diesem Kollektiv Primärinfektionen sind. Zur Expositionsprophylaxe sollten deshalb immunkompromittierte Patienten Kontakte mit ansteckenden Tuberkulosekranken bis zur Sputumkonversion des Erkrankten meiden. Die Pentamidin-Inhalation zur PCP-Prophylaxe sollte in abgeschlossenen Räumen mit ausreichender Entlüftung ohne Anwesenheit von Mitpatienten erfolgen, da durch Hustenattacken Aerosole entstehen können, durch die Anwesende mit Tuberkuloseerregern infiziert werden können.

Grundlage der CDC-Empfehlungen ist die Durchführung eines Intrakutantests (Mendel-Mantoux) mit 10TE, der bei Diagnose einer HIV-Infektion, vor Organtransplantation und Steroidtherapie prinzipiell empfohlen wird [142]. Eine Primärprophylaxe (neuerdings: Behandlung der latenten Infektion) wird bei positivem Intrakutantest (Induration $>5 \mathrm{~mm}$ ), Konversion (positiver Test bei negativem Vorbefund oder Zunahme der Induration $>10 \mathrm{~mm}$ ) oder ansteckender Tuberkulose im Umfeld des Patienten empfohlen. Eine aktive Tuberkulose muss durch entsprechende Diagnostik ausgeschlossen werden. Der Intrakutantest soll bei negativem Ausfall oder signifikanter Verbesserung des

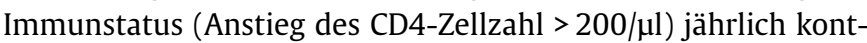
rolliert werden, um falsch negative Reaktionen zu erfassen. Eine generelle Anergie-Diagnostik wird nicht für notwendig erachtet. Auf eine Sekundärprophylaxe kann verzichtet werden, wenn die Tuberkulose mit einem etablierten Therapieregime ausreichend lange therapiert wurde [142]. 
In Deutschland wird eine Tuberkulin-Testung bei Immundefizienz nicht konsequent durchgeführt. Aufgrund der niedrigeren Inzidenz der Tuberkulose werden Komorbiditäten von Immundefizienz und Tuberkulose seltener beobachtet. Die Evidenz für die Effektivität des von den CDC empfohlenen Vorgehens ist daher geringer. Die generelle Durchführung von Tuberkulin-Testen ist jedoch nur sinnvoll, wenn bei einem positiven Ergebnis auch eine entsprechende Therapie veranlasst wird. Die Entscheidung für eine präventive Therapie oder ein abwartendes Vorgehen sollte daher unter Berücksichtigung individueller Risikofaktoren getroffen werden: hierzu gehören Schwere und erwartete Dauer des Immundefizits, Begleiterkrankungen oder Komedikationen, die die Toxizität der präventiven Therapie erhöhen sowie die Compliance des Patienten (Grad III). Unabhängig vom Ergebnis des Intrakutantests sollten immunkompromittierte Kontaktpersonen eines infektiösen Tuberkulosekranken eine Chemoprophylaxe erhalten (Tab. 15) (Grad II) [142]. Alternativ zur Isoniazid-Prophylaxe ist inzwischen die Kurzzeitkombination von Rifampicin und Pyrazinamid etabliert, die in einer Studie bei HIVpositiven Patienten eine vergleichbare Effektivität zeigte [143]. Allerdings wurden inzwischen mehrere Fälle von Leberversagen bei HIV-negativen Patienten unter dieser Kombination beobachtet, so dass die Indikation für dieses Prophylaxeregime derzeit zurückhaltend und nur unter der Voraussetzung einer engmaschigen Überwachung gestellt werden sollte [144]. Interaktionen der Antituberkulotika mit Virustatika oder Immunsuppressiva sind wie bei der Therapie zu berücksichtigen. So ist Rifampicin bei gleichzeitiger Gabe von Proteaseinhibitoren oder nichtnukleosidalen Inhibitoren der reversen Transkriptase kontraindiziert (Grad III) [87].

\section{Nichttuberkulöse Mykobakterien (NTM)}

Die klinische Bedeutung von NTM als Verursacher pulmonaler Infektionen hat in den letzten Jahren ständig zugenommen. Bei HIV-Infizierten ist Mycobacterium avium complex (MAC) der wichtigste Vertreter dieser Erregergruppe. Weitere NTM, die insbesondere bei pulmonaler Vorerkrankung und Immundefizit Infektionen verursachen, sind M. kansasii, M. abscessus, M. xenopi und M. malmoense. Eine Expositionsprophylaxe ist angesichts des ubiquitären Vorkommens der Erreger nicht möglich. Die Übertragung von Mensch zu Mensch hat epidemiologisch keine Bedeutung. Eine Primärprophylaxe wird in internationalen Leit-

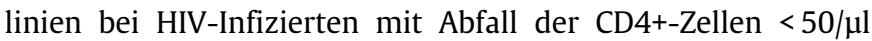
empfohlen [87]. Aufgrund der Interaktion mit Proteaseinhibitoren ist der Einsatz von Rifabutin bei Patienten unter antiretroviraler Kombinationstherapie problematisch. Clarithromycin zeigte gegenüber Plazebo einen signifikanten Schutzeffekt [145], und Azithromycin war in einer vergleichenden Studie effektiver als Rifabutin [146]. Die wirksamere Kombination von Azithromycin und Rifabutin wird wegen der hohen Nebenwirkungsrate nicht empfohlen. Es sollten deshalb bevorzugt die Makrolide Clarithromycin und Azithromycin in Monotherapie eingesetzt werden (Grad I) [87]. Alternativ kann beim heutigen Stand der HAART vor Einleitung einer Primärprophylaxe zunächst der Erfolg der antiviralen Therapie hinsichtlich des Immunstatus abgewartet werden (Grad III).

Nach Therapie einer disseminierten MAC-Infektion wird eine lebenslange Sekundärprophylaxe mit den gleichen Präparaten empfohlen (Grad I) [87]. Bei Patienten mit anderen Immundefizienzen ist keine Chemoprophylaxe etabliert.

\section{Pilze \\ Pneumocystis carinii}

Vor Etablierung prophylaktischer Konzepte betrug die Inzidenz der PCP nach Herz-Lungentransplantation über 80\% [147]. Unter Chemoprophylaxe ist sie auf $2 \%$ (Nieren-Tx) bis 26\% (Lungen-Tx) gesunken, wobei die meisten Fälle unter nicht konsequent durchgeführter Prophylaxe auftraten [148]. Eine randomisierte Studie bei Herztransplantierten zeigte eine hohe Effektivität von Co-trimoxazol [149]. Die Chemoprophylaxe wird meist bereits im ersten Monat begonnen und sollte in jedem Fall für die ersten 12 Monate beibehalten werden (Grad II) [148]. Am häufigsten wird Co-trimoxazol in einer Dosis von $960 \mathrm{mg} 3-7 \mathrm{x} /$ Woche verordnet. Da bei Lungenempfängern auch nach dem ersten Jahr ein erhöhtes Risiko bestehen bleibt, empfehlen einige Zentren die Prophylaxe lebenslang durchzuführen (Grad III). Die prophylaktische Verabreichung von Co-trimoxazol reduziert gleichzeitig das Auftreten von Infektionen durch $L$. monozytogenes und $N$. asteroides, bei nierentransplantierten Patienten auch die Inzidenz von Harnwegsinfektionen [150].

Bei HIV-Infizierten wird eine Primärprophylaxe begonnen, wenn

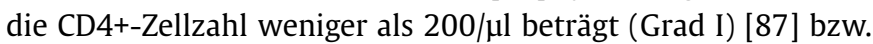
bei Nachweis einer oropharyngealen Candidose oder einer AIDSdefinierenden Erkrankung (Grad II) [87]. Co-trimoxazol ist in einer Dosierung von einer Forte-Tablette/d $(960 \mathrm{mg})$ signifikant wirksamer als Alternativregime wie Dapson oder Pentamidin (Grad I) [151,152], wirkt auch in niedrigeren Dosen $(1 \times 480 \mathrm{mg} / \mathrm{d}$ oder $3 \times 960 \mathrm{mg} /$ Woche) bei besserer Verträglichkeit zuverlässig (Grad II) [87]. Bei Kontraindikationen oder Unverträglichkeit kann auf Dapson ausgewichen werden, das trotz seiner Sulfonamidstruktur von der Mehrzahl der Patienten mit Co-trimoxazolunverträglichkeit toleriert wird [153]. Eine weitere Alternative stellt inhalatives Pentamidin dar, dessen Vorteil die gute Verträglichkeit bei fehlender systemischer Distribution ist. Die überlegene Wirkung von Co-trimoxazol gegenüber den Vergleichssubstanzen ist besonders bei fortgeschrittenem Immundefekt mit CD4-Zahlen $<100 / \mu l$ evident [154]. Steigt unter antiretroviraler Therapie die CD4+-Zellzahl stabil auf > 200 Zellen/ $\mu \mathrm{l}$ an, kann die Prophylaxe 3-6 Monate nach Überschreiten des Grenzwertes beendet werden (Grad II) [87].

Bei Patienten mit Systemerkrankungen besteht unter immunsuppressiver Therapie ebenfalls ein erhöhtes Risiko, an einer PCP zu erkranken. Das Risiko ist von der Grunderkrankung abhängig und scheint nach den vorliegenden Beobachtungen am niedrigsten bei der rheumatoiden Arthritis und am höchsten bei der Wegener'schen Granulomatose zu sein. Eine Co-trimoxazolprophylaxe wird daher insbesondere bei Patienten mit Wegener'scher Granulomatose, anderen Vaskulitiden und schwerem SLE unter Therapie mit Glukokortikoiden und Cyclophosphamid empfohlen (Grad II) [155]; bei anderen Grunderkrankungen und Immunsuppressiva wie Methotrexat sollte die Indikation individuell nach Nutzen und Risiko abgewogen werden; hierbei ist die Bestimmung der CD4+-Zellzahl im Blut möglicherweise hilfreich. 


\section{Aspergillus spp.}

Bei Lungentransplantierten ist von saprophytären Pilzinfektionen in etwa $10 \%$ auszugehen. Eine postoperative invasive Aspergillusinfektion verläuft in 60-75\% letal [156,157]. In einzelnen Transplantationszentren wird deshalb in der postoperativen Phase bis zur Abheilung der Bronchialanastomosen eine $2 \times$ tägliche Inhalation von Amphotericin B oder liposomalem Amphotericin propagiert, ohne dass hierzu kontrollierte Studien vorliegen [158]. Diese Prophylaxe wird jedoch nicht von allen Patienten vertragen und kann zu ausgeprägten Bronchialobstruktionen führen. Neuere Daten aus unkontrollierten Studien legen die Möglichkeit einer oralen Prophylaxe mit Azolen nahe [159]. Eine Aspergillusprophylaxe bei HIV-Infizierten ist wegen des seltenen Auftretens der Infektion nicht etabliert.

\section{Virusinfektionen Cytomegalovirus}

Zur Expositionsprophylaxe sollten CMV-seronegative, immunkompromittierte Patienten nur Blutprodukte von CMV-negativen Spendern erhalten; der Einsatz entsprechender Filter sollte beachtet werden. Bei der Versorgung kleiner Kinder im häuslichen Umfeld dieser Risikopatienten ist eine sorgfältige Hygiene notwendig. Nach Transplantation wird bei CMV-Hochrisikokonstellationen (Empfänger seronegativ/Spender seropositiv, intensivierte Immunsuppression) Ganciclovir in unterschiedlichen prophylaktischen Dosierungen über 2 bis 20 Wochen eingesetzt. In kontrollierten Studien bei Herz-, Leber- und Lungentransplantierten konnte hierunter eine signifikante Reduktion der CMVErkrankungen und Infektionen nachgewiesen werden (Grad II) [160]. Bei Nierentransplantierten wurde auch ein Effekt unter Primärprophylaxe mit Valaciclovir beobachtet [161]. Von einzelnen Transplantationsgruppen wird die zusätzliche Gabe von CMV-Hyperimmunglobulin propagiert, ohne dass valide prospektive Studien vorliegen [162]. Der Stellenwert einer oralen Ganciclovir-Prophylaxe, die bei Lebertransplantierten mit Erfolg getestet wurde [163], ist unklar. Ebenso fehlen valide Daten zur Kosten-Nutzen-Relation. In vielen Zentren wird daher die parenterale Ganciclovir-Prophylaxe auf Hochrisikokonstellationen (Spender positiv/Empfänger negativ) während der ersten 12 Wochen beschränkt.

Ein alternativer Ansatz ist die präemptive Therapie, bei der eine regelmäßige, meist wöchentliche Bestimmung der CMV-Antigenämie oder der quantitativen CMV-PCR im Plasma erfolgt. Eine Ganciclovir-Therapie wird begonnen, sobald ein vorher festgelegter Grenztiter überschritten ist (z. B. 4/400 000 Zellen [Antigen] oder 2000-5000 Kopien/ml [PCR]). Der positive Vorhersagewert eines solchen Befundes für den Ausbruch der CMV-Erkrankung lag bei Lebertransplantierten bei $64,3 \%$, der negative Vorhersagewert bei 95,7 [61]. Dieses Vorgehen scheint bei „Normal"-Risikokonstellation meist ausreichend, um manifeste Erkrankungen zu verhindern und reduziert die Rate unnötiger und potenziell toxischer Behandlungen (Grad II) $[164,165]$. In einer vergleichenden Studie bei Lebertransplantierten wurde die orale Ganciclovirprophylaxe über 6 Wochen mit der präemptiven Therapie mit intravenösem Ganciclovir über 7 Tage bei Auftreten einer pp65-Antigenämie verglichen [166]. Mit beiden Ansätzen wurden invasive CMV-Erkrankungen verhindert; darüber hinaus fand sich bei keinem der mit oralem Ganciclovir behandelten Pa- tienten bzw. nur einem Patienten der Kontrollgruppe ein akutes CMV-Syndrom.

Bei HIV-infizierten CMV-seropositiven Patienten wird aufgrund des ungünstigen Nutzen-Risikoprofils und der hohen Kosten keine Primärprophylaxe mit oralem Ganciclovir empfohlen. Ledig-

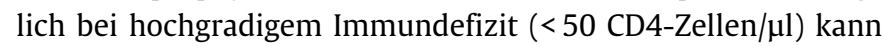
eine Ganciclovir-Prophylaxe im Einzelfall erwogen werden (Grad I) [87]. Aciclovir ist in dieser Indikation unzureichend wirksam, und unter Valaciclovir wurde zwar eine geringere Erkrankungsrate, gleichzeitig aber eine tendenziell gesteigerte Mortalität beobachtet [167]. Obwohl mit den derzeit verfügbaren Virustatika eine CMV-Erkrankung nicht zu heilen ist, gibt es im Gegensatz zur CMV-Retinitis keine validen Daten zur Sekundärprophylaxe pulmonaler CMV-Infektionen.

\section{Herpes-simplex-Virus}

HSV-Pneumonien waren zu Beginn der Lungentransplantationsära eine gefürchtete Frühkomplikation. Deshalb wird in den meisten Transplantationsprogrammen eine Prophylaxe mit Aciclovir in den ersten 3 postoperativen Monaten durchgeführt, sofern kein Ganciclovir verabreicht wird (Grad III). Von einzelnen Transplantationsgruppen wird eine lebenslange Beibehaltung dieser Prophylaxe propagiert. Bei HIV-Infizierten sind HSVPneumonien selten. Eine Primärprophylaxe ist daher nicht erforderlich (Grad III) [87]. Bei hartnäckig rezidivierenden und/oder sehr schwer verlaufenden mukokutanen Herpes-Infektionen kommt eine orale Suppressionstherapie mit Aciclovir, Valaciclovir oder Famciclovir infrage.

\section{Influenza $A$}

Immunkompromittierte Patienten gehören zur Gruppe der Risikopatienten, für die eine jährliche Schutzimpfung ausdrücklich empfohlen wird [136]. Bei Organtransplantierten ist der Erfolg dieser Maßnahme zwar nicht durch aussagekräftige Studien zu belegen, andererseits gilt die Impfung im Hinblick auf die Provokation von Abstoßungsreaktionen als ungefährlich. Nach Nierenund Herztransplantation ist die Antikörperbildung infolge der Immunsuppression vermindert, dennoch werden in der Mehrzahl protektive Antikörpertiter erreicht [168]. Auch niedrige Antikörpertiter gegen Influenza verringern das Risiko an sekundären Komplikationen, Influenza-bedingten Krankenhauseinweisungen und Todesfällen (Grad II) [169]. Bei HIV-Infektion nimmt die Immunantwort mit zunehmendem Krankheitsstadium ab.

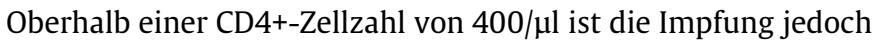
hocheffektiv [170]. Eine antivirale Chemoprophylaxe mit Amantadin scheint bei frühzeitiger Einnahme einen partiellen Infektionsschutz für Immunkompromittierte zu gewährleisten. Aufgrund des Nebenwirkungsprofils wird der Einsatz des Präparates nur bei überzeugender Umgebungsanamnese z.B. im Rahmen von nosokomialen Infektionen unter Abwägung des individuellen Nutzen-Risikoprofils empfohlen (Grad III). 
15 Pirofsky B, Kinzey DM. Intravenous immune globulins. A review of their use in selected immunodeficiency and autoimmune diseases. Drugs 1992; 43: 6-14

$\begin{array}{ll}\text { CMV } & =\text { Cytomegalie-Virus } \\ \text { EBV } & =\text { Epstein-Barr-Virus } \\ \text { FNAB } & =\text { Feinnadelaspirationsbiopsie } \\ \text { GNEB } & =\text { gramnegative Enterobakterien } \\ \text { HAART } & =\text { hochaktive antiretrovirale Therapie } \\ \text { HSV } & =\text { Herpes simplex-Virus } \\ \text { IPA } & =\text { invasive pulmonale Aspergilose } \\ \text { MAC } & =\text { Mycobacterium-avium-Complex } \\ \text { NTM } & =\text { nichttuberkulöse Mykobakterien } \\ \text { OLB } & =\text { offene Lungenbiopsie } \\ \text { OP } & =\text { organisierende Pneumonie } \\ \text { OLB } & =\text { offene Lungenbiopsie } \\ \text { OP } & =\text { organisierende Pneumonie } \\ \text { PCP } & =\text { Pneumocystis carinii-Pneumonie } \\ \text { RSV } & =\text { Respiratory syncytial-Virus } \\ \text { TBB } & =\text { transbronchiale Biopsie } \\ \text { VZV } & =\text { Varizella zoster-Virus }\end{array}$

Literatur

${ }^{1}$ Deutsche Stiftung für Organtransplantation. Organspende und Transplantation, Deutschland 1999. Neu-Isenburg: DSO, 2000

2 UNAIDS. Epidemic update - Report on the global HIV/AIDS epidemic, December 2000. http://www.unaids.org/epidemic_update/report_dec00/index_dec.html.

${ }^{3}$ Hughes WT, Armstrong D, Bodey GP et al. Guidelines for the use of antimicrobial agents in neutropenic patients with unexplained fever. J Infect Dis 1990; 161: 381 - 396

${ }^{4}$ Pizzo PA. Management of fever in patients with cancer and treatment-induced neutropenia. N Engl J Med 1993; 328: 1323 - 1332

${ }^{5}$ Maschmeyer G, Link H, Hiddemann W et al. Empirische antimikrobielle Therapie bei neutropenischen Patienten. Ergebnisse einer Studie der Arbeitsgruppe Infektionen in der Hämatologie der Paul-Ehrlich-Gesellschaft. Med Klin 1994; 89: 114-123

${ }^{6}$ Barloon TJ, Galvin JR, Mori M et al. High-resolution ultrafast chest CT in the clinical management of febrile bone marrow transplant patients with normal or nonspecific chest roentgenogramms. Chest 1991; 99: 928 -933

${ }^{7}$ Klein JO, Mortimer EA. Use of pneumococcal vaccine in children. Pediatrics 1978; 61: $312-322$

${ }^{8}$ Bridgen ML, Patullo AL. Prevention and management of overwhelming postsplenectomy infection - An update. Crit Care Med 1999; 27: $836-842$

${ }^{9}$ Heffelfinger JD, Dowell SF, Jorgensen JH et al. Management of communnity-acquired pneumonia in the era of pneumococcal resistance. Arch Intern Med 2000; 160: 1399-1408

${ }^{10}$ Co-operative group for the study of immunoglobulin in chronic lymphocytic leukaemia. Intravenous immunoglobulin for the prevention of infection in chronic lymphocytic leukaemia. N Engl J Med 1988; 319: $902-907$

${ }^{11}$ Griffiths H, Brennan V, Lea J. Crossover study of Immunoglobulin replacement therapy in patients with low-grade-B-cell tumors. Blood 1989; 73: 366-368

12 Boughton BJ, Jackson N, Lim S et al. Randomized trial of intravenous immunoglobulin prophylaxis for patients with chronic lymphocytic leukaemia and secondary hypogammaglobulinaenia. Clin Lab Haematol 1995; 17: $75-80$

${ }^{13}$ Molica S, Musto P, Chiurazzi F. Prophylaxis against infections with low-dose intravenous immunoglobulins in chronic lymphocytic leukemia. Results of a crossover study. Haematologica 1996; 81: $121-126$

${ }^{14}$ Schedel I. Application of immunoglobulin preparations in multiple myeloma. In: Morell A, Nydegger UE. Clinical use of immunoglobulins. New York: Academic Press, 1986: 123-132
${ }^{16}$ Wahn V, Eibl M, Spaith P. Anwendung polyvalenter intravenöser Immunglobuline in der Therapie. Mschr Kinderheilkd 1999; 147: $293-297$

${ }^{17}$ Carratala J, Roson B, Fernandez-Sevilla A et al. Bacteremic Pneumonia in Neutropenic Patients with Cancer. Arch Intern Med 1998; 158: $868-872$

${ }^{18}$ Hughes WT, Armstrong D, Bodey GP. Guidelines for the use of antimicrobial agents in neutropenic patients with unexplained fever. Clin Infect Dis 1997; 25: $551-573$

${ }^{19}$ Kuhlmann JE, Fishman E, Siegelman S. Invasive pulmonary aspergillosis in acute leukemia: characteristic findings in CT, the CT halo sign, and the role of CT in early diagnosis. Radiology 1985; 157: 611 - 619

${ }^{20}$ Heussel C, Kauczor H, Heussel G. Early detection of pneumonia in febrile neutropenic patients: Use of thin-section CT. Am J Roentgenol 1997; 169: $1347-1353$

${ }^{21}$ Shelhammer JH, Toews GB, Masur $\mathrm{H}$ et al. Respiratory disease in the immunosuppressed patient. Ann Intern Med 1992; 117: 415-431

22 Sickles E, Young V, Greene W. Pneumonia in acute leukemia. Ann Intern Med 1973; 79: 528-534

${ }^{23}$ Stover DE, Zaman MB, Hajdu SI et al. Bronchoalveolar lavage in the diagnosis of diffuse pulmonary infiltrates in the immunosuppressed host. Ann Intern Med 1984; 101: 1 - 7

${ }^{24}$ Saito H, Anaissie EJ, Morice RC et al. Bronchoalveolar lavage in the diagnosis of pulmonary infiltrates in patients with acute leukemia. Chest 1988; 94: 745-749

${ }^{25}$ Marra R, Pagano L, Pagliari G et al. The yield of bronchoalveolar lavage in the etiological diagnosis of pneumonia in leukemia and lymphoma patients. Eur J Hematol 1993; 51: 256-258

${ }^{26}$ Ewig S, Glasmacher A, Ulrich B et al. Pulmonary infiltrates in neutropenic patients with acute leukemia during chemotherapy: outcome and prognostic factors. Chest 1998; 114: 444-451

${ }^{27}$ Ewig S, Torres A, Riquelme R et al. Pulmonary complications in patients with haematologic malignancies treated at a respiratory ICU. Eur Respir J 1998; 12: 116-122

${ }^{28}$ von Eiff M, Zühlsdorf M, Roos $\mathrm{N}$ et al. Pulmonary infiltrates in patients with hematologic malignancies Clinical usefulness of non-invasive bronchoscopic procedures. Eur J Haematol 1995; 54: 157 - 162

${ }^{29}$ Rano A, Agusti C, Jimenez P et al. Pulmonary infiltrates in non-HIV immunocompromised patients: a diagnostic approach using non-invasive and bronchoscopic procedures. Thorax 2001; 56: 379-387

${ }^{30}$ Antonelli M, Conti G, Riccioni L et al. Noninvasive positive-pressure ventilation via face mask during bronchoscopy with BAL in high-risk hypoxemic patients. Chest 1996; 110: $724-728$

${ }^{31}$ Pennington JE, Feldman NT. Pulmonary infiltrates and fever in patients with hematologic malignancy. Assessment of transbronchial biopsy. Am J Med 1977; 62: 581 - 587

32 Phillips MJ, Knight RK, Green M. Fibreoptic bronchoscopy and diagnosis of pulmonary lesions in lymphoma and leukemia. Thorax 1980; 35: $19-25$

${ }^{33}$ Cazzadori A, Di Perri G, Todeschini G et al. Transbronchial biopsy in the diagnosis of pulmonary infiltrates in immunocompromised patients. Chest 1995; 107: $101-105$

${ }^{34}$ Wong PW, Stefanec T, Brown K et al. Role of fine-needle aspirates of focal lung lesions in patients with hematologic malignancies. Chest 2002; 121: $527-532$

${ }^{35}$ White DA, Wong PW, Downey R. The Utility of Open Lung Biopsy in patients with hematologic malignancies. Am J Respir Crit Care Med 2000; 161: 723-729

${ }^{36}$ von Eiff M, Zühlsdorf M, Roos N et al. Pulmonary fungal infections in patients with hematological malignancies - diagnostic approaches. Ann Hematol 1995; 70: 135-141

${ }^{37}$ Kahn FW, Jones JM, England DM. The role of bronchoalveolar lavage in the diagnosis of invasive pulmonary aspergillosis. Am J Clin Pathol 1986; 86: $518-523$

${ }^{38}$ Glasmacher A, Marklein G, Just-Nübling G et al. Diagnostik invasiver Mykosen bei neutropenischen Patienten mit hämatologischen Systemerkrankungen. Dtsch Med Wschr 1998; 123: 157-160

${ }^{39}$ Horvath J, Dummer S. The use of respiratory tract cultures in the diagnosis of invasive aspergillosis. Am J Med 1996; 100: 171 - 178

${ }^{40}$ Sulahian A, Taboluret M, Ribaud P. Comparison of an enzyme immunoassay and latex agglutination test for detection of galactomannan 
in the diagnosis of aspergillosis. Eur J Clin Microbiol Infect Dis 1996; 15: $139-145$

${ }^{41}$ Peters SG, Meadows JA, Gracey DR. Outcome of respiratory failure in hematologic malignancy. Chest 1988; 94: 99-102

${ }^{42}$ Ramphal R. Is monotherapy for febrile neutropenia still a viable alternative? Clin Infect Dis 1999; 29: 508 - 514

${ }^{43}$ Maschmeyer G, Link H, Hiddemann W et al. Pulmonary infiltrations in febrile patients with neutropenia. Cancer 1994; 73: 2296-2304

${ }^{44}$ Maschmeyer G, Beinert T, Buchheidt D et al. Diagnostik und Therapie von Lungeninfiltraten bei febrilen neutropenischen Patienten. Dtsch Med Wschr 1999; 124: S18-S23

${ }^{45}$ Rubin RH, Young LS. Clinical approach to infection in the compromised host. New York $^{3}$ : Plenum Publishers, 1994: 629-705

${ }^{46}$ Acrasoy SM, Kotloff RM. Lung transplantation. N Engl J Med 1999; 14: $1081-1091$

${ }^{47}$ Kramer MR, Marshall SE, Starnes VA et al. Infectious complications after heart lung and single lung transplantation. Chest 1993; 104: $681-685$

${ }^{48}$ Horvarth J, Dummer S, Loyd J et al. Infection in the transplanted and native lung after single lung transplantation. Chest 1993; 104: 681-685

49 Paradis IL, Williams P. Infection after lung transplantation. Semin Respir Infect 1993; 8: 207-215

${ }^{50} \mathrm{Ho}$ M. Advances in understanding cytomegalovirus infection after transplantation. Transplant Proc 1994; 26: 7-11

51 Paterson D, Singh N. Invasive aspergillosis in transplant recipients. Medicine 1999; 78: $123-138$

52 Fishman JA, Rubin RH. Infection in organ-transplant recipients. N Engl J Med 1998; 338: 1741 - 1751

${ }^{53}$ Westney GE, Kesten S, DeHoyos A et al. Aspergillus infection in single and double lung transplant recipients. Transplantation 1996; 61: 915-919

${ }^{54}$ Keenan RJ, Lega ME, Dummer JS. Cytomegalovirus serologic status and postoperative infection correlated with risk of developing chronic rejection after pulmonary transplantation. Transplantation 1991; 51: 433

55 O'Brian JD, Ettinger NA. Pulmonary complications of liver transplantation. Clin Chest Med 1996; 17: 99-114

${ }^{56}$ Hohlfeld J, Niedermeyer J, Hamm $\mathrm{H}$ et al. Seasonal onset of bronchiolitis obliterans syndrome in lung transplant recipients. J Heart Lung Transplant 1996; 15: $888-894$

${ }^{57}$ Kesten S, Chaparro C. Mycobacterial infections in lung transplant recipients. Chest 1999; 115: 741-745

${ }^{58}$ Malouf MA, Glanville AR. The Spectrum of Mycobacterial infection after lung transplantation. Am J Respir Crit Care Med 1999; 160: $1611-1616$

${ }^{59}$ Sternberg RI, Baughman RP, Dohn MN et al. Utility of bronchoalveolar lavage in assessing pneumonia in immunosuppressed renal transplant recipients. Am J Med 1993; 95: 358 - 364

60 Egan JJ, Barber L, Lomax J. Detection of human cytomegalovirus antigenaemia: a rapid diagnostic technique for predicting cytomegalovirus infection/pneumonitis in lung and heart transplant recipients. Thorax 1995; 50: 59

${ }^{61}$ Humar A, Gregson D, Caliendo AM et al. Clinical utility of quantitative cytomegalovirus viral load determination for pedicting cytomegalovirus disease in liver transplant recipients. Transplantation 1999; 68: $1305-1311$

${ }^{62}$ Caillot D, Casanovas O, Bernard A. Improved management of invasive pulmonary in neutropenic patients using early thoracic computed tomographic scan and surgery. J Clin Oncol 1997; 5: 139-147

${ }^{63}$ Johnson PC, Hogg KM, Sarosi GA. The rapid diagnosis of pulmonary infections in solid organ transplant recipients. Semin Respir Infect 1990; 5 : $2-9$

${ }^{64}$ Torres A, Ewig S, Insausti J et al. Etiology and microbial patterns of pulmonary infiltrates in patients with orthotopic liver transplantation. Chest 2000; 117: 494-502

${ }^{65}$ Dichter JR, Stewart J, Shelhammer JH. Approach to the immunocompromised host with pulmonary infiltrates. Hematol/Oncol Clin North Am 1993; 7: 887-912

${ }^{66}$ Reichenberger F, Habicht J, Matt P et al. Diagnostic yield of bronchoscopy in histologically proven invasive pulmonary aspergillosis. Bone Marrow Transplant 1999; 24: 1195-1199

${ }^{67}$ Pomerance A, Madden B, Burke MM et al. Transbronchial biosy in heart and lung transplantations: clinicopathologic correlations. J Heart Lung Transplant 1995; 14: $761-773$
${ }^{68}$ Boehler A. Prospective study of the value of transbronchial lung biopsy after lung transplantation. Eur Respir J 1996; 4: 658 - 662

${ }^{69}$ Trulock EP. Flexible bronchoscopy in lung transplantation. Clin Chest Med 1999; 20: 77-87

70 Paterson D, Singh N, Gayowski T. Pulmonary nodules in liver transplant recipients. Medicine 1998; 77: 50-58

${ }^{71}$ Bart ME, Webber BL, Wesley RA. Prospective evaluation of aspiration needle, cutting needle, transbronchial, and open lung biopsy in patients with pulmonary infiltrates. Ann Thorac Surg 1981; 32: $146-153$

72 Gregg CR. Drug interactions and anti-infective therapies. Am J Med 1999; 106: 227-237

${ }^{73} \mathrm{Kim}$ JS, Lee KS, Koh EM et al. Thoracic involvement of systemic lupus erythematodes: clinical, pathologic, and radiologic findings. J Comput Assist Tomogr 2000; 24: 9-18

${ }^{74}$ Murin S, Wiedemann HP, Matthay RA. Pulmonary manifestations of systemic lupus erythematodes. Chest 1998; 19: 641 - 665

${ }^{75}$ Santamauro JT, White DA. Respiratory infections in HIV-negative immunocompromised patients. Curr Opin Pulm Med 1996; 2: 253 - 258

${ }^{76}$ Godeau B, Coulant-Perrone V, Huong DI et al. Pneumocystis carinii pneumonia in the course of connective tissue disease: report of 34 cases. J Rheumatol 1994; 21: 246 - 251

77 Mok CC, Yuen KY, Lau CS. Nocardiosis in systemic lupus erythematodes. Semin Arthritis Rheum 1997; 26: 675-680

${ }^{78}$ Feng PH, Tang TH. Tuberculosis in patients with systemic lupus erythematodes. Ann Rheum Dis 1982; 41: 11 - 18

${ }^{79}$ Maini R, St Clair EW, Breedvelt F et al. Infliximab or placebo in rheumatoid arthritis patients receiving concomittant methotrexate: a randomised phase III trial. Lancet 1999; 354: 1932-1939

${ }^{80}$ Sullivan WD, Hurst DJ, Harmon CF. A prospective evaluation emphasizing pulmonary involvement in patients with mixed connective tissue disease. Medicine 1984; 63: $92-107$

${ }^{81}$ Fenlon HM, Doran M, Sant SM. High resolution chest-CT in systemic lupus erythematodes. Am J Roentgenol 1996; 166: 301 - 306

82 Evans SA, Hopkinson ND, Kinnear WJ. Respiratory disease in systemic lupus erythematodes: correlation with results of laboratory tests and histological appearance of muscle biopsy specimens. Thorax 1992; 47: $957-967$

${ }^{83}$ Flabouris A, Myburgh J. The utility of open lung biopsy in patients requiring mechanical ventilation. Chest 1999; 115: 811 - 817

${ }^{84}$ Agostini C, Trentin L, Zambello and Semenzato G. HIV-1 and the lung. Am Rev Respir Dis 1993; 147: 1038 - 1049

${ }^{85}$ Bofil M, Lipman M, McLaughlin JE et al. Changes in lung lymphocyte populations reflect those seen in peripheral blood in HIV-1 positive individuals. Eur Respir J 1998; 11: 548-553

${ }^{86}$ Clerici M, Shearer GM. The Th1-Th2 hypothesis of HIV infection: new insights. Immunol Today 1994; 15: 575-581

${ }^{87}$ USHS/IDSA Prevention of Opportunistic Infections Working Group. Guidelines for the prevention of opportunistic infections in persons infected with human immundodeficiency virus. Ann Intern Med 1999; 131: $873-896$

88 Mayaud C, Cadranel J. AIDS and the lung in a changing world. Thorax 2001; 56: $423-426$

${ }^{89}$ Bericht des Aids-Zentrums im Robert Koch-Institut über aktuelle epidemiologische Daten, Quartalsbericht IV/98. Berlin, 1999

${ }^{90}$ Wallace JM, Hansen NI, Lavange L et al. Respiratory disease trends in the pulmonary complications of HIV infected study cohort. Am J Respir Crit Care Med 1997; 155: $72-80$

${ }^{91}$ Brodt $\mathrm{H}$, Kamps B, Gute P et al. Changing incidence of AIDS-defining illnesses in the era of antiretroviral combination therapy. AIDS 1997; 11: $1731-1738$

${ }^{92}$ Sullivan JH, Moore RD, Keruly JC et al. Effect of antiretroviral therapy on the incidence of bacterial pneumonia in patients with advanced HIV infection. Am J Respir Crit Care Med 2000; 162: 64-67

${ }^{93}$ Feldman C, Glatthaar M, Morar R et al. Bacteremic pneumococcal pneumonia in HIV-seropositive and HIV-seronegative adults. Chest 1999; 116: 107 - 114

${ }^{94}$ Baughman RP, Dohn M, Frame P. The continuing utillity of bronchoalveolar lavage to diagnose opportunistic infection in AIDS patients. Am J Med 1994; 97: 515 - 525

${ }^{95}$ Koch A, Kothe H, Braun J et al. Inzidenz bakterieller Pneumonien bei HIV-positiven Patienten unter Co-trimoxazol oder Pentamidin. Pneumologie 1998; 52: 614-621 
${ }^{96}$ Miller RF, Foley NM, Kessel D et al. Community acquired lobar pneumonia in patients with HIV infection and AIDS. Thorax 1994; 49: $367-368$

${ }^{97}$ Afessa B, Green W, Chiao J et al. Pulmonary complications of HIV-infection. Chest 1998; 113: 1225-1229

${ }^{98}$ Waxmann A, Goldie S, Brett-Smith H et al. Cytomegalovirus as a primary pulmonary pathogen in AIDS. Chest 1997; 111: 128-134

${ }^{99}$ Mylonakis E, Barlam TF, Flanigan T et al. Pulmonary aspergillosis and invasive disease in AIDS. Chest 1998; 114: 251 - 262

100 Janoff EN, O'Brien J, Thompson P et al. Streptococcus pneumoniae colonization, bacteremia and immune response among persons with human immunodeficiency virus infection. J Infect Dis 1993; 167: 49-56

${ }^{101}$ De Gracia J, Miravitlles M, Mayordomo C et al. Empiric treatments impair the diagnostic yield of BAL in HIV-positive patients. Chest 1997; 111: $1180-1186$

102 Weldon-Linne CM, Phone DP, Bourassa R. Bronchoscopy specimens in adults with AIDS. Chest 1990; 98: 24-28

${ }^{103}$ Cadranel J, Gillet-Juvin K, Antoine M et al. Site-directed bronchoalveolar lavage and transbronchial biopsy in HIV-infected patients with pneumonia. Am J Respir Crit Care Med 1995; 152: 1103-1106

104 Caiffa WT, Graham NMH, Vlahov D. Bacterial pneumonia in adult populations with Human Immundeficiency Virus infection. Am J Epidemiol 1993; 138: 909-922

105 Ewig S, Nachtsheim KH, Seuffert HM et al. Protected bronchoalveolar lavage for the diagnosis of HIV-associated pneumonia. J Bronchol 1998; 5: 25-33

106 Jules-Elysee KM, Stover DE, Zaman MB et al. Aerosolized pentamidine: Effect on diagnosis and presentation of Pneumocystis carinii pneumonia. Ann Intern Med 1990; 112: 750 - 757

107 Schlatter CE, Kuster H, Lüthy R et al. Sputumuntersuchung zur Diagnostik der Pneumocyctis-carinii-Pneumonie bei HIV-Infizierten. Dtsch Med Wschr 1994; 119: 1151 - 1155

${ }^{108}$ Schaberg T, Dalhoff K, Ewig S et al. Empfehlungen zur Therapie der ambulant erworbenen Pneumonie. Pneumologie 1998; 52: 450-462

109 Baron AD, Hollander H. Pseudomonas aeruginosa bronchopulmonary infection in late Human Immunodeficiency Virus disease. Am Rev Respir Dis 1993; 148: 992 - 996

110 Deutsches Zentralkomitee zur Bekämpfung der Tuberkulose. Richtlinien zur medikamentösen Behandlung der Tuberkulose im Erwachsenen- und Kindesalter. Pneumologie 2001; 55: 494-511

111 Schaberg T. HIV und Tuberkulose. In: Konietzko N, Loddenkemper R (Hrsg): Tuberkulose. Stuttgart: Thieme Verlag, 1999: 199-214

112 Burman WJ, Jones BE. Treatment of HIV-related tuberculosis in the era of effective antiretroviral therapy. Am J Respir Crit Care Med 2001; 164: 7-12

113 Gordin FM, Sullam PM, Shafran SD et al. A randomized, placebo-controlled study of rifabutin added to a regimen of clarithromycin and ethambutol for treatment of disseminated infection with Mycobacterium avium complex. Clin Infect Dis 1999; 28: 1080-1085

114 Glasmacher A, Just-Nübling G, Molitor E. Therapie invasiver Mykosen bei neutropenischen Patienten mit hämatologischen Systemerkrankungen. Dtsch Med Wschr 1998; 123: 191 - 194

115 Walsh TJ, Finberg RW, Arndt C et al. Liposomal amphotericin B for empirical therapy in patients with persistent fever and neutropenia. N Engl J Med 1999; 340: 764 - 771

$116 \mathrm{Rex} J \mathrm{H}$, Walsh TJ, Sobel JD et al. Practice guidelines for the treatment of candidiasis. Clin Infect Dis 2000; 30: 662-678

117 Bodey GP. The epidemiology of Candida glabrata and Candida albicans fungemia in immunocompromised patients with cancer. Am J Med 2002; 112: 380-385

118 Denning DW, Lee JY, Hosttler JS. Mycoses Study Group multicenter trial of oral itraconazole therapy for invasive aspergillosis. Am J Med 1994; 97: 135 - 144

${ }^{119}$ Denning DW. Efficacy and safety of voriconazole in the treatment of acute invasive aspergillosis. Clin Infect Dis 2002; 34: 563- 571

${ }^{120}$ Arathoon EG. Randomized, double blind, multicenter study of caspofungin versus amphotericin B for treatment of oropharyngeal and esophageal candidiasis. Antimicrob Agents Chemother 2002; 46: $451-457$

${ }^{121}$ Reichenberger F, Habicht J, Kaim A et al. Lung resection for invasive pulmonary aspergillosis in neutropenic patients with hematologic diseases. Am J Respir Crit Care Med 1998; 158: 885-890

122 Sattler FR, Cowan R, Nielsen DM et al. Trimethoprim-sulfamethoxazole compared with pentamidine for treatment of Pneumocystis cari- nii pneumonia in the acquired immunodeficiency syndrome. Ann Intern Med 1988; 109: 280-287

${ }^{123}$ Hughes W, Leoung G, Kramer F et al. Comparison of Atovaquone (566C80) with trimethoprim-sulfamethoxazole to treat Pneumocystis carinii pneumonia in patients with AIDS. N Engl J Med 1993; 328 : $1521-1527$

${ }^{124}$ Safrin S, Lee BL, Sande MA. Adjunctive folinic acid with trimethoprim-sulfamethoxazole for Pneumocystis carinii pneumonia in AIDS patients is associated with an increased risk of therapeutic failure and death. J Infect Dis 1994; 170: 912 - 917

125 Conte JE, Chernoff D, Feigal DW et al. Intravenous or inhaled pentamidine for treating Pneumocystis carinii pneumonia in AIDS. Ann Intern Med 1990; 113: $203-209$

${ }^{126}$ Medina I, Mills J, Leoung G et al. Oral therapy for Pneumocystis carinii pneumonia in the acquired immonodeficiency syndrome. $\mathrm{N}$ Engl J Med 1990; 323: 776-782

${ }^{127}$ Bozzette SA, Sattler FR, Chiu J et al. A controlled trial of early adjunctive treatment with corticosteroids for Pneumocyctis carinii pneumonia in the acquired immunodeficiency syndrome. N Engl J Med 1990; 323: $1451-1457$

${ }^{128}$ Pareja JG, Garland R, Koziel H. Use of adjunctive corticosteroids in severe adult non-HIV Pneumocystis carinii pneumonia. Chest 1998; 113: $1215-1224$

129 Blanshard C, Benhamou Y, Dohin E et al. Treatment of AIDS-associated gastrointestinal cytomegalovirus infection with foscarnet and ganciclovir: A randomized comparison. J Infect Dis 1995; 172: $622-628$

${ }^{130}$ Hecht DW, Snydman DR, Crumpacker CS et al. Ganciclovir for treatment of renal transplant - associated primary cytomegalovirus pneumonia. J Infect Dis 1988; 157: 187-190

131 Martin DF, Sierra-Madero J, Walmsley S et al. A controlled trial of valganciclovir as induction therapy for Cytomegalovirus Retinitis. N Engl J Med 2002; 346: 1119-1126

${ }^{132}$ Kern WV, Beyer J, Böhme A et al. Infektionsprophylaxe bei neutropenischen Patienten. Dtsch Med Wschr 125; 2000: 1582-1588

${ }^{133}$ Deutsch E, End A, Grimm M et al. Early bacterial infections in lung transplant recipients. Chest 1993; 104: 1412 - 1416

${ }^{134}$ Chaparro C, Kesten S. Infections in lung transplant recipients. Clin Chest Med 1997; 18: 339-351

135 Corris PA. Prophylaxis post-transplant. The role of monitoring surveillance bronchoscopy and antimicrobials. Clin Chest Med 1997; 18: $311-318$

${ }^{136}$ STIKO/Ständige Impfkommission. Impfempfehlungen der Ständigen Impfkommission am Robert Koch-Institut. Epidemiologisches Bulletin 2000; $2: 9-20$

${ }^{137}$ Gebo KA, Moore RD, Keruly JC et al. Risk factors for pneumococcal disease in human immunodeficiency virus-infected patients. J Infect Dis 1996; 173 : $857-862$

${ }^{138}$ Ammann AJ, Addiego J, Wara DW. Polyvalent pneumococcal-polysaccharide immunization of patients with sickle-cell anemia and patients with splenectomy. N Engl J Med 1977; 297: 897-900

139 Chattopadhyay B. Splenectomy, pneumococcal vaccination and antibiotic prophylaxis. Br J Hosp Med 1989; 41: 172 - 174

${ }^{140}$ Funk EM, Schlimok G, Ehret W et al. Standortbestimmung der Impfund Antibiotikaprophylaxe bei Splenektomie. Teil I: Erwachsene. Chirurg 1997; 68: 586 - 590

${ }^{141}$ Di Padova F, Durig M, Wadstrom J et al. Role of spleen in immune response to polyvalent pneumococcal vaccine. Br Med J 1983; 287 $1829-1832$

${ }^{142}$ ATS/CDC Statement Committee on Latent Tuberculosis Infection. Targeted tuberculin testing and treatment of latent tuberculosis infection. MMWR 2000; 49: 1-51

143 Gordin F, Chaisson RE, Matts JP et al. Rifampin and Pyrazinamide vs Isoniazid for prevention of tuberculosis in HIV-infected persons. JAMA 2000; 283: 1445 - 1449

${ }^{144}$ American Thoracic Society. Update: Fatal and severe liver injuries associated with rifampin and pyrazinamide for latent tuberculosis infection, and revisions in American Thoracic Society /CDC recommendations - United States 2001. Am J Respir Crit Care Med 2001; 164 : $1319-1320$

145 Pierce M, Crampton S, Henry D et al. A randomized trial of clarithromycin as prophylaxis against disseminaed Mycobacterium avium complex infection in patients with advanced acquired immunodeficiency syndrome. N Engl J Med 1996; 335: 384-391 
${ }^{146}$ Havlir DV, Dube MP, Sattler FR et al. Prophylaxis against disseminated Mycobacterium avium complex with weekly Azithromycin, daily Rifabutin, or both. N Engl J Med 1996; 335: 392 - 398

147 Gryzan S, Paradis IL, Zeevi A et al. Unexpectedly high incidence of Pneumocystis carinii infection after lung-heart transplantation. Implications for lung defense and allograft survival. Am Rev Respir Dis 1988; 137: 1268 - 1274

148 Gordon SM, LaRosa SP, Kalmadi S et al. Should prophylaxis for Pneumocystis carinii pneumonia in solid organ transplant recipients ever be discontinued? Clin Inf Dis 1999; 28: 240-246

149 Olsen SL, Renlund DG, O'Conell JB. Prevention of Pneumocystis carinii pneumonia in cardiac transplant recipients by trimethoprim-sulfamethoxazole. Transplantation 1993; 56: 359-362

${ }^{150}$ Fishman JA. Pneumocystis carinii and parasitic infections in transplantation. Infect Dis Clin North Am 1995; 9: 1045-1047

151 Schneider ME, Hoepelman AIM, Eeftinck Schattenkerk JKM et al. A controlled trial of aerosolized pentamidine or trimethoprim-sulfamethoxazole as primary prophylaxis against pneumocystis carinii pneumonia in patients with human immunodeficiency virus infection N Engl J Med 1992; 327: 1836-1840

${ }^{152}$ Bozzette SA, Finkelstein DM, Spector SA. A randomized trial of three antipneumocystis agents in patients with advanced human immunodeficiency virus infection. N Engl J M 1995; 332: 693-699

${ }^{153}$ Hill HE, Wallace M, Kennedy C. Prophylaxis of Pneumocystis carinii pneumonia with dapsone; an evaluation of toxicity and cross-reactivity with trimethoprim-sulfamethoxazole. Amsterdam: International Conference on AIDS, 1992; PoB 3304

154 Bucher HC, Griffith Ll, Guyatt GH et al. Meta-analyses of prophylactic treatments against PCP and Toxoplasma encephalitis in HIV-infected patients. J Acquir Immune Defic Syndr Hum Retrovirol 1997; 15: $104-114$

155 Vernovsky I, Dellaripa PF. Pneumocystis carinii pneumonia prophylaxis in patients with rheumatic diseases undergoing immunsuppressive therapy. J Clin Rheumatol 2000; 6: 94-101

156 Paradowski LJ. Saprophytic fungal infections and lung transplantation - revisited. J Heart Lung Transplant 1997; 16: 524-531

157 Duncan SR, Grgurich WF, Iacono AT et al. A comparison of ganciclovir and acyclovir to prevent cytomegalovirus after lung transplantation. Am J Respir Crit Care Med 1994; 150: 146-152
${ }^{158}$ Calvo V, Borro JM, Morales P et al. Antifungal prophylaxis during the early postoperative period of lung transplantation. Chest 1999; 115 : $1301-1304$

${ }^{159}$ Hamacher J, Spiliopoulos A, Kurt AM et al. Pre-emptive therapy with azoles in lung transplant patients. Eur Respir J 1999; 13: 180-186

${ }^{160}$ Duncan SR, Gregurich WF, Iacono AT et al. A comparison of ganciclovir and acyclovir to prevent cytomegalovirus after lung transplantation. Am J Respir Crit Care Med 1994; 150: 146-152

${ }^{161}$ Lowance D, Neumayer HH, Legendre CM. Valacyclovir for the prevention of cytomegalovirus disease after renal transplantation. N Engl J Med 1999; 340: $1462-1470$

162 Gutierrez CA, Chaparro C, Krajden M et al. Cytomegalovirus viremia in lung transplant recipients receiving ganciclovir and immune globulin. Chest 1998; 113: 924-932

163 Gane E, Saliba F, Valdecasas GJ. Randomized trial of efficacy and safety of oral ganciclovir in the prevention of cytomegalovirus disease in liver transplant recipients. Lancet 1997; 350: 1729-1733

${ }^{164}$ Kusne S, Grossi P, Irish W et al. Cytomegalovirus pp65 antigenemia as a guide for preemptive therapy: a cost effective strategy for prevention of cytomegalovirus disease in adult liver transplant recipients. Transplantation 1999; 68: 1125 - 1131

165 Egan JJ, Lomax J, Barber L et al. Preemptive treatment for the prevention of cytomegalovirus disease in lung and heart transplant recipients. Transplantation 1998; 65: 747-752

166 Singh N, Paterson DL, Gayowski T et al. Cytomegalovirus antigenemia directed pre-emptive prophylaxis with oral versus i.v. ganciclovir for the prevention of cytomegalovirus disease in liver transplant recipients: a randomized, controlled trial. Transplantation 2000; 15 : $717-722$

${ }^{167}$ Feinberg JE, Hurwitz S, Cooper D et al. A randomized, double-blind trial of valaciclovir prophylaxis for cytomegalovirus disease in patients with advanced human immunodeficciency virus infections. J Infect Dis 1998; 177: 48-56

${ }^{168}$ Freund S, Wagner D, Pethig $\mathrm{K}$ et al. Influenza vaccination in heart transplant recipients. J Heart Lung Transplant 1999; 18: 220-225

${ }^{169}$ Gross PA, Hermogenes AW, Sacks HS et al. The efficacy of influenza vaccine in elderly persons: a metaanalysis and review of the literature. Ann Int Med 1995; 123: 518-527

170 Tasker SA, Treanor JJ, Paxton WB et al. Efficacy of influenza vaccination in HIV-infected persons: a randomized, double-blind, placebocontrolled trial. Ann Intern Med 1999; 131: 430-433 